KCP-613-5845

Distribution Category UC-706

Approved for public release; distribution is unlimited.

\title{
GROUND PENETRATING RADAR MINI-CRADA FINAL REPORT
}

Richard Swanson, FM\&T;

Greg Stump, Vermeer Manufacturing Co.; and

Gary Weil, EnTech Engineering, Inc.

Published September 1996

Final Report

Small Business Initiative

Cooperative Research and Development Agreement KCP-94-1005

DISTRIBUTION OF THIS DOCUMENT IS UNLIMITED

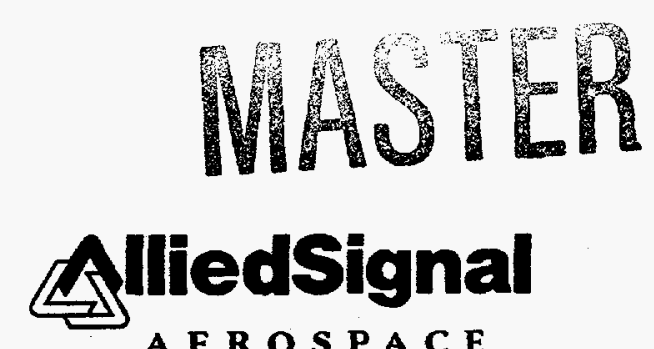

A E R O S P A C E 


\section{DISCLAIMER}

This report was prepared as an account of work sponsored by an agency of the United States Government. Neither the United States Government nor any agency thereof, nor any of their employees, makes any warranty, express or implied, or assumes any legal liability or responsibility for the accuracy, completeness, or usefulness of any information, apparatus, product, or process disclosed, or represents that its use would not infringe privately owned rights. Reference herein to any specific commercial product, process, or service by trade name, trademark, manufacturer, or otherwise does not necessarily constitute or imply its endorsement, recommendation, or favoring by the United States Government or any agency thereof. The views and opinions of authors expressed herein do not necessarily state or reflect those of the United States Government or any agency thereof. 


\section{DISCLAIMER}

Portions of this document may be illegible in electronic image products. Images are produced from the best available original document. 


\title{
Small Business Initiative
}

Cooperative Research and Development Agreement

KCP-94-1005

\author{
GROUND PENETRATING RADAR \\ Mini-CRADA \\ FINAL REPORT \\ 06/11/96 \\ EnTech, Vermeer, AlliedSignal
}

Principle Investigators:

Greg Stump

Vermeer Manufacturing Co.

Richard Swanson

AlliedSignal Federal Manufacturing \& Technology (FM\&T)/

Kansas City Plant (KCP)

Gary Weil

EnTech Engineering, Inc.

Prepared Under Contract Number DE-ACO4-76-DP00613 for the

United States Department of Energy

(Technical Publication Reference \# KCP-613-5845) 
Table of Contents

Project Summary ...........................................................ii

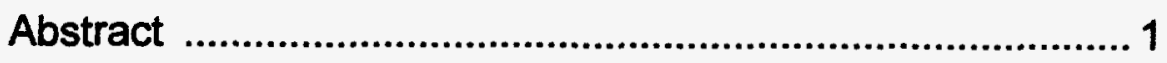

I. Project Description .......................................................... 2

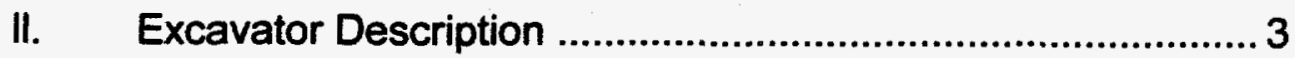

III. GPR Literature Review ...................................................

IV. Description of GPR data image presentation format.............. 4

V. Determination of Material Dielectric Constant .......................6

VI. Commercial GPR System Descriptions \& Field Test Data ..... 8

VII. KCP GPR System Description........................................... 12

VIII. Impulse vs. Swept Frequency GPR.....................................17

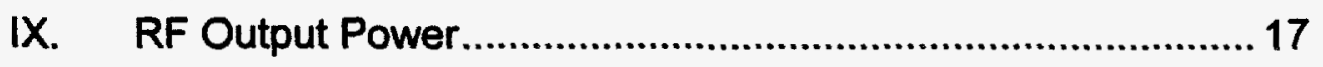

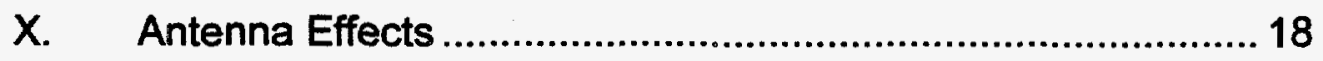

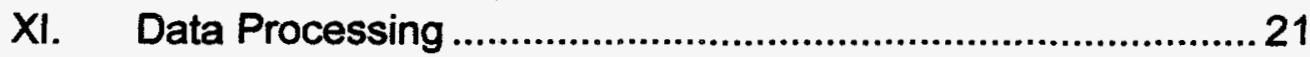

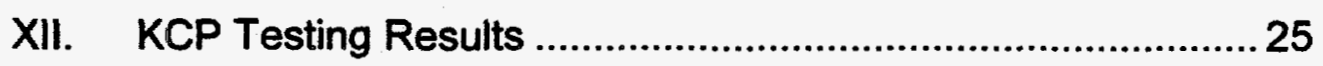

XIII. Environment Description ...................................................28

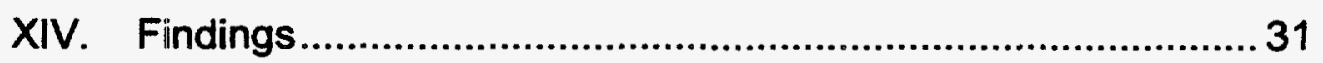

XV. Recommendation for Future Research .................................32

XVI. Recommendations for GPR Systems..................................33

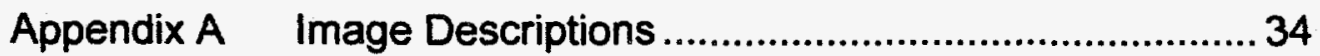

Appendix B AlliedSignal GPR System Photo ................................36 


\section{Project Summary}

1. Background - Ground penetrating radar (GPR) systems are in common use for performing various types of geological related surveys. The purpose of this project was to jointly determine the feasibility of using a GPR to assess ease of excavability prior to and during excavation operations. Ease of excavability can be related to the cuttability of the rock material. Other information potentially available from the GPR can possibly include optimum rock cutting geometry and hazard detection, ie., detection of buried power lines, telephone lines, pipes, etc.

2. Description - This project is supported by AlliedSignal's expertise in radar \& testing systems and hardware development together with EnTech's knowledge of GPR systems and Vermeer's excavation experience. The goal is to develop GPR system requirements optimized for excavation applications. The team performed laboratory and field testing, including commercial GPR systems as well as a GPR developed around an AlliedSignal Network Analyzer instrument, to evaluate system and environment parameters. Depths to 10 feet were of primary interest.

3. Benefits to DOE - This project exercised key processes and technologies essential to the KCP mission including: Materials Analysis/Evaluation (T22), Test Equipment Fabrication (T43), Non-Destructive Testing (T50), and Software Engineering (T55). Additionally, potential dual use for GPR technology exists in military or DOE applications relating to mapping / excavating hazardous sites.

4. Economic Impact - Potential benefits to industry include:

a) Enabling better project planning, improved equipment maintenance scheduling, and more efficient application of equipment

b) Development of equipment which can be added to U.S. manufactured construction equipment to give U.S. products a quality, technological, and economic competitive advantage

c) Development of new domestic and export business for U.S. companies

d) Reduced contamination and spills from accidentally damaged underground oil, gas, and chemical pipelines

5. Project Status - This project, CRADA \# KCP-94-1005, has been completed. 


\section{Project Summary (cont.)}

6. DOE Facility, Points of Contact -

As prime contractor to the U.S. Department of Energy (DOE), AlliedSignal FM\&T I Kansas City Plant (KCP) has produced non-nuclear components for nuclear weapons since 1949. This work has spawned a diversity of manufacturing technologies that are applicable to development of GPR.

a) Ken Bauer

U.S. Dept. of Energy

Kansas City Area Office

P.O. Box 410202

2000 E. 95th St.

Kansas City, MO 64141

Phone: 816-997-3917

FAX: 818-997-5059 b) Richard Swanson

AlliedSignal FM\&T , DOE Kansas City Plant

P.O. Box 419159

2000 E. 95th St.

Kansas City, MO 64141

Phone: 816-997-7356

FAX: 816-997-7169

7. Industrial Partners, Points of Contact -

EnTech Engineering is a professional engineering, consulting and independent testing firm specializing in remote sensing \& non-destructive testing techniques. Vermeer is a design, manufacturing and distribution company for equipment used in construction and agricultural markets, both domestic and world-wide.
a) Gary Weil
EnTech Engineering,
b) Greg Stump
Incorporated
1846 Craig Park Court
St. Louis, MO 63146
Phone: 314-434-5255
Vermeer
Manufacturing
Company
P.O. Box 200
FAX: $314-434-3270$
Pella, lowa 50219
Phone: 515-621-7759

8. Project Examples - The project Final Report provides figures showing GPR images from some of the project's test sites.

9. Technology Commercialization - Although a formal plan for technology commercialization related to this project has not been established, recommendations for further research and development are presented in the CRADA Final Report. 


\title{
Ground Penetrating Radar (GPR) Mini-CRADA
}

\author{
FINAL REPORT \\ $06 / 11 / 96$
}

GPRFNL_A, B, C, D.DOC

Richard Swanson

\section{ABSTRACT}

This purpose of this project was to determine the feasibility of using ground penetrating radar (GPR) to assess the ease of excavability prior to and during trenching operations. The project partners were EnTech Engineering Inc., Vermeer Manufacturing Co., and AlliedSignal Federal Manufacturing \& Technology (FM\&T) / Kansas City Plant (KCP). Commercial GPR's were field tested as well as a system developed at AlliedSignal FM\&T. The AlliedSignal GPR was centered around a HP8753 Network Analyzer instrument. Commercial GPR antennas were connected to the analyzer and data was collected under control of software written for a notebook PC. Images of sub-surface features were generated for varied system parameters including: frequency, bandwidth, FFT windowing, gain, antenna orientation, and surface roughness conditions. Depths to 10 feet were of primary interest in this project.

Although further development is required, this project has demonstrated that GPR can be used to identify transitions between different sub-surface conditions, as in going from one rock type to another. Additionally, the average relative dielectric constant of the material can be estimated which can be used to help identify the material. This information can be used to characterize an excavation site for use in budgeting a job. A real-time GPR would provide the operator with sub-surface images that could help with setting the optimum "feed and speed" rates of the trenching machine.

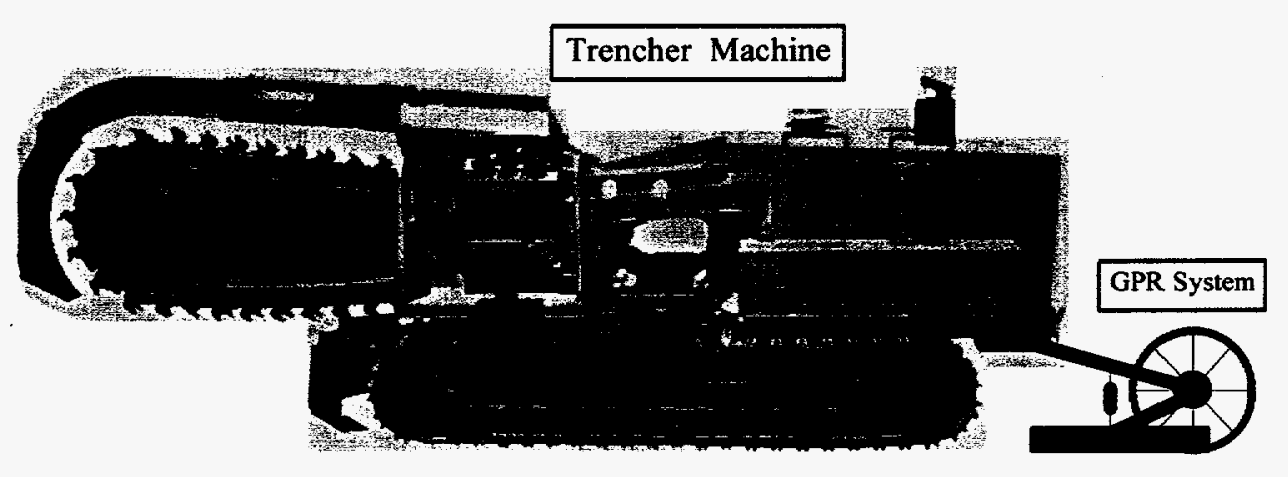

Possible Trencher / GPR System Configuration 
I. Project Description-

A. KCP CRADA Work-

The Cooperative Research and Development Agreement (CRADA) project partners were:

AlliedSignal FM\&T Incorporated- Kansas City Plant (KCP)

Kansas City, Missouri

EnTech Engineering, Incorporated

St. Louis, Missouri

Vermeer Manufacturing Company

Pella, lowa

The purpose of this CRADA was to jointly determine the feasibility of using a ground penetrating radar (GPR) to assess the ease of excavability prior to and during excavation operations. An operational GPR system could be used to characterize sites prior to excavation to provide information useful to budgeting job costs. This information could be used to help determine what type and size of Excavator machinery is optimum for the job.

A commonly used subsurface survey method involves the use of sonicbased systems. These systems can be very effective, but can involve the use of a large network of widely spaced geo-phones. This increases the expense and decreases the flexibility of doing subsurface surveys. Ground penetrating radar offers the potential for a more flexible and adaptive system.

A real-time, Excavator mounted, GPR system could provide information to the operator that would help in setting optimum "feed and speed" rates of the Excavator, thus improving the productivity of the machine. Additionally, with GPR information about the extent of the rock being excavated, timely equipment maintenance could be scheduled.

Other information potentially available from the GPR could include optimum rock cutting geometry (which is related to the rock shelf orientation) and hazard detection (buried pipes and cables). 


\section{B. CRADA Work Plan-}

The project work plan derived from the CRADA statement of work (SOW) consisted of the following steps:

\begin{tabular}{|c|c|c|}
\hline SOW Task Description & Project Steps & Results Summary \\
\hline Task 1: System Requirements & 1.1 Establish Project Goals & $\begin{array}{l}\text { 1.1 Wrote GPR Project Definition } \\
\text { Document }\end{array}$ \\
\hline $\begin{array}{l}\text { Task 2: Proof-of-Concept } \\
\text { System }\end{array}$ & $\begin{array}{l}\text { 2.1 Evaluate Commercial GPR } \\
\text { state-of-the-art } \\
2.2 \text { GPR Literature Search }\end{array}$ & $\begin{array}{l}\text { 2.1 Field tested commercial GPR units. } \\
2.2 \text { Collected data on previous work done } \\
\text { in the use of GPR for subsurface survey. }\end{array}$ \\
\hline $\begin{array}{l}\text { Task 3: Design and assemble } \\
\text { proof-of-concept GPR }\end{array}$ & $\begin{array}{l}\text { 3.1 Determine KCP GPR system } \\
\text { requirements } \\
\text { 3.2 Design \& build KCP GPR }\end{array}$ & $\begin{array}{l}3.1 \text { KCP GPR system based on HP8753 } \\
\text { Network Analyzer was built. }\end{array}$ \\
\hline $\begin{array}{l}\text { Task 4: Lab test proof-of- } \\
\text { Concept GPR }\end{array}$ & 4.1 Perform KCP GPR lab tests. & $\begin{array}{l}\text { 4.1 Extensive testing of KCP GPR was } \\
\text { performed to prove-in the system. }\end{array}$ \\
\hline $\begin{array}{l}\text { Task 5: Data collection through } \\
\text { field tests of proof-of-Concept } \\
\text { GPR }\end{array}$ & $\begin{array}{l}\text { 5.1 Perform KCP GPR field tests } \\
\text { on-site at KCP and at off-site } \\
\text { locations in KC area. }\end{array}$ & $\begin{array}{l}\text { 5.1 GPR data collected at sites with } \\
\text { known sub-surface features (indoors \& } \\
\text { outdoors), in addition to uncharacterized } \\
\text { sites. }\end{array}$ \\
\hline Task 6: Analyze field test data & $\begin{array}{l}\text { 6.1 Analyze KCP GPR data } \\
\text { using MATLAB }\end{array}$ & $\begin{array}{l}\text { 6.1 GPR subsurface scans were produced. } \\
\text { GPR performance was evaluated for } \\
\text { different subsurface configurations and for } \\
\text { different GPR characteristics. }\end{array}$ \\
\hline Task 7: Document the results & $\begin{array}{l}\text { 7.1 Submit status reports to KCP } \\
\text { New Business and DOE. } \\
7.2 \text { Write final report. }\end{array}$ & 7.1 Reports on file with KCP. \\
\hline
\end{tabular}

1. Table 1: Project Task Description

II. Excavator Description-

A. A typical earth excavator has the following performance characteristics:

1. Digging widths: $10 "-28$ "

2. Digging depths: $0^{\prime \prime}-96^{\prime \prime}$

3. Speed: 15 feet $/ \mathrm{min}$. (Soil), 2 feet $/ \mathrm{min}$. (rock)

4. Instrumentation Capability: RPM of trencher chain, Torque on trencher boom, Rate of travel

III. GPR Literature Review-

A. Introduction to Subsurface Radar, Daniels, Gunton, Scott, IEEE Proceedings, Vol 135 (Aug, 1988) -

This reference is a good source of information on work done to date and presents GPR design strategies. The paper discusses the use of orthogonally polarized transmitting and receiving antennas to reduce antenna coupling, that is especially useful in discriminating planar interfaces and long thin targets. The authors discuss how the ground material under the antenna forms part of the dielectric environment whose properties modify the antennas behavior. Thus any nonuniformity in this environment, such as changing surface conditions, will degrade the antenna performance and increase image distortion. The received 
GPR signal consists of a convolution of the desired "target" response and the set of other scatters in the ground with the antenna characteristics.

"Clutter" in the GPR image is also due to the large number of potential scatters in the ground. These give rise to multipath interaction and so some prior knowledge of the type of target being sought is needed to decide which parts of the GPR image is clutter and which is due to the target. Since the ground is not generally homogeneous it is not possible to calibrate a GPR system for a given ground condition to reduce the clutter.

B. Determination of the Best Ground Penetrating Radar Source Signal Type for the Accurate Location of Underground Utilities, Thain, Defense Technical Information Center, Report No. CR-88.013 (Sept, 1988) -

This is a report of tests performed using impulse and FM-CW GPR designs. Included are numerous Time Domain Reflection (TDR) plots of pipes buried in a test tank. In particular they use a HP8510 Network Analyzer for the FM-CW GPR, this is similar to the HP8753 which was used for the our CRADA project. They conclude that the frequency domain GPR provided the highest performance capabilities.

C. Ground Penetrating Radar Geophysical Research Methods, Saarenketo, et. al., Finnish Geotechnical Society, (1992) -

This report discusses the use and interpretation of impulse-GPR imaging for use in geophysical profiling of subsurface features. They summarize that to become fully familiar in the use of GPR and in the interpretation of results, it is necessary to obtain extensive practical experience.

D. Application of Impulse Radar to Civil Engineering, Ulriksen, Lund University of Technology (Sweden), (1982) -

This thesis provides a study of the uses of GPR. The author discusses the use of UHF-band impulse GPR to determine true range to a point or planar target, and the RF propagation velocity in the material. The author makes use of the hyperbolic function for analysis of point targets.

IV. Description of GPR data image presentation format-

A. In general the GPR data presented in this report is displayed as an image slice of sub-surface reflections as the GPR is moved over the surface of the ground. The 'X-axis' is the direction of physical travel across the surface, where as the 'Z-axis' is the reflections from subsurface features at descending depths. The strength of the returns can be represented in a number of different ways including gray scale brightness, color, and line graph.

B. The process for generating a KCP GPR image involves taking the Time Domain Reflection (TDR) data from the 'X-axis' scan across the surface and combining them into one large two dimensional data matrix. This matrix is then display as an image using MATLAB, see Figure 1. 
MATLAB is a commercial software package with capability to manipulate matrices and display data in image form. MATLAB has various image processing commands including 'shading interp' which interpolates between data points to 'smooth' the image, and 'colormap' which allows changing of the color scheme.

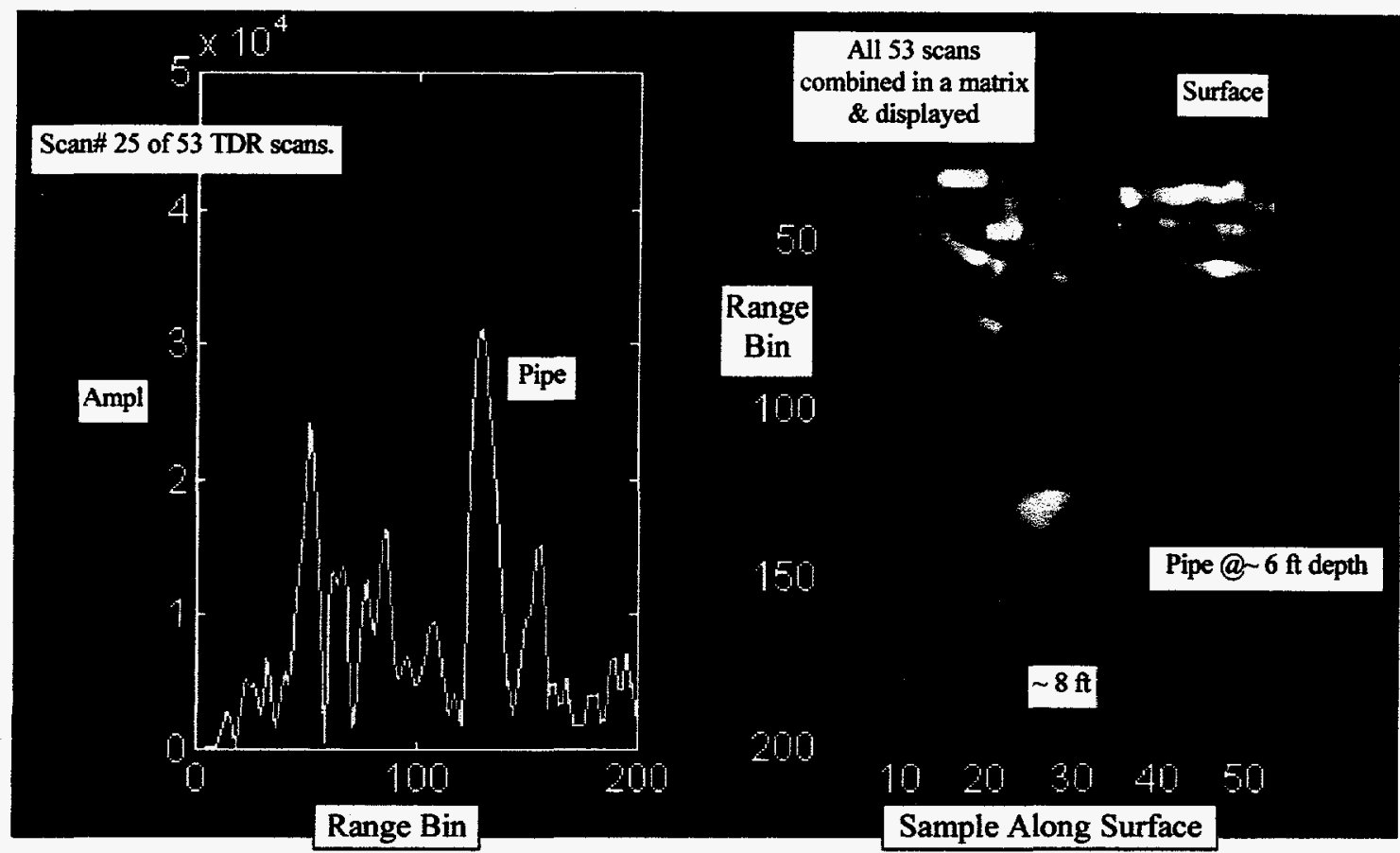

Figure 1: Process of Creating GPR Image from Mulit-TDR Scans

C. X-axis and Z-axis labels in KCP GPR images indicate the sample point index in each direction. $X$-axis labels are sample points 'along track' across the surface and are typically 2 inches apart. Z-axis sample points are GPR range cells in depth. The number of points are determined by the Network Analyzer NUMPOINTS setting. Since radar measures a two-way range (time delay) to the target and back, range measured with the GPR must be divided by 2 to get one-way range to the target from the surface( [TDR_Time / 2] * [Speed-of-light]). The depth of the return is also dependent on the TDR TIMESPAN and the dielectric constant $\left(e_{r}\right)$ of the ground:

Z-scale_factor for measurement sample points in depth = [ ( $c^{*}\{($ TIMESPAN / NUMPOINTS $\left.) / 2\} / \operatorname{sqr}\left(e_{r}\right)\right]$
Example -
$c=3 E+08 \mathrm{~m} / \mathrm{s}$,
$e_{r}=3$
TIMESPAN $=40 \mathrm{~ns}$
NUMPOINTS=201 (range bins)
Z-scale_factor $=0.018 \mathrm{~m} / \mathrm{pt}(0.68 \mathrm{in} / \mathrm{pt})$ 
V. Determination of Material Dielectric Constant-

A. The determination of material dielectric constant (relative electric permittivity) can be accomplished by making use of the hyperbola produced in a GPR image as a result of a broad beam antenna scanned over a subsurface point target (pipe, etc.). This hyperbola can be seen as a distortion in the image, however it can also be used as information to estimate the dielectric constant of the material (assuming it is relatively homogeneous) surrounding the point target.

Since the dielectric constant determines the speed of the RF signal in the material, the shape of the hyperbola will be dependent on the dielectric constant. This is similar to the analysis presented in the Thesis by Ulriksen. However he concentrates on equations that correct for the dielectric constant in the estimation of true depths to targets. In our project the emphasis is on the determination of the dielectric constant. An equation for the estimation of dielectric constant is developed below:

General equation of a vertical hyperbola with origin at 0,0 (See Figure 2):

$$
(z / a)^{2}-(x / b)^{2}=1
$$

where: $\quad z=$ vertical distance from antenna to point on hyperbola

$x=$ horizontal distance from antenna to vertex of

hyperbola

$a=$ vertical distance from surface to vertex of hyperbola

$b=$ horizontal distance from focus of hyperbola to point on hyperbola

and:

$$
b=\operatorname{sqrt}\left\{x^{2} /\left([z / a]^{2}-1\right)\right\}
$$

For equilateral hyperbola (origin at 0,0 \& orthogonal asymptotes):

$$
a=b
$$

A hyperbola in a radar image in air (free space) will satisfy the equation a $=\mathrm{b}$ since the dielectric constant $\left(e_{r}\right)$ equals 1 . However in a typical GPR image the apparent dimensions of a hyperbola as measured from the image will not satisfy $a=b$ because the dielectric constant is greater than 1 . The relationship is:

$$
a_{m} / \operatorname{sqrt}\left(e_{r}\right)=b \quad=\operatorname{sqrt}\left\{x_{m}{ }^{2} /\left(\left[z_{m} / a_{m}\right]^{2}-1\right)\right\}
$$

Where $a_{m}, z_{m}$, and $x_{m}$ are values measured from a GPR image that has not been precompensated for the $e_{r}$. The dimensions $a_{m}$ and $z_{m}$ are one-way measurements ( Distance $=\left[\right.$ [TDR_Time / 2 ] ${ }^{*}$ [Speed-of-light] $)$. Note that $x_{m}$ is an actual physical measurement and thus not dependent on the value of $e_{r}$. It is then observed from the right-hand side of the equation that $b$ is not dependent on $e_{r}$, thus $a_{m}$ must be. Solving for $e_{r}$ :

$$
e_{r}=\left(z_{m}^{2}-a_{m}^{2}\right) / x_{m}^{2}
$$




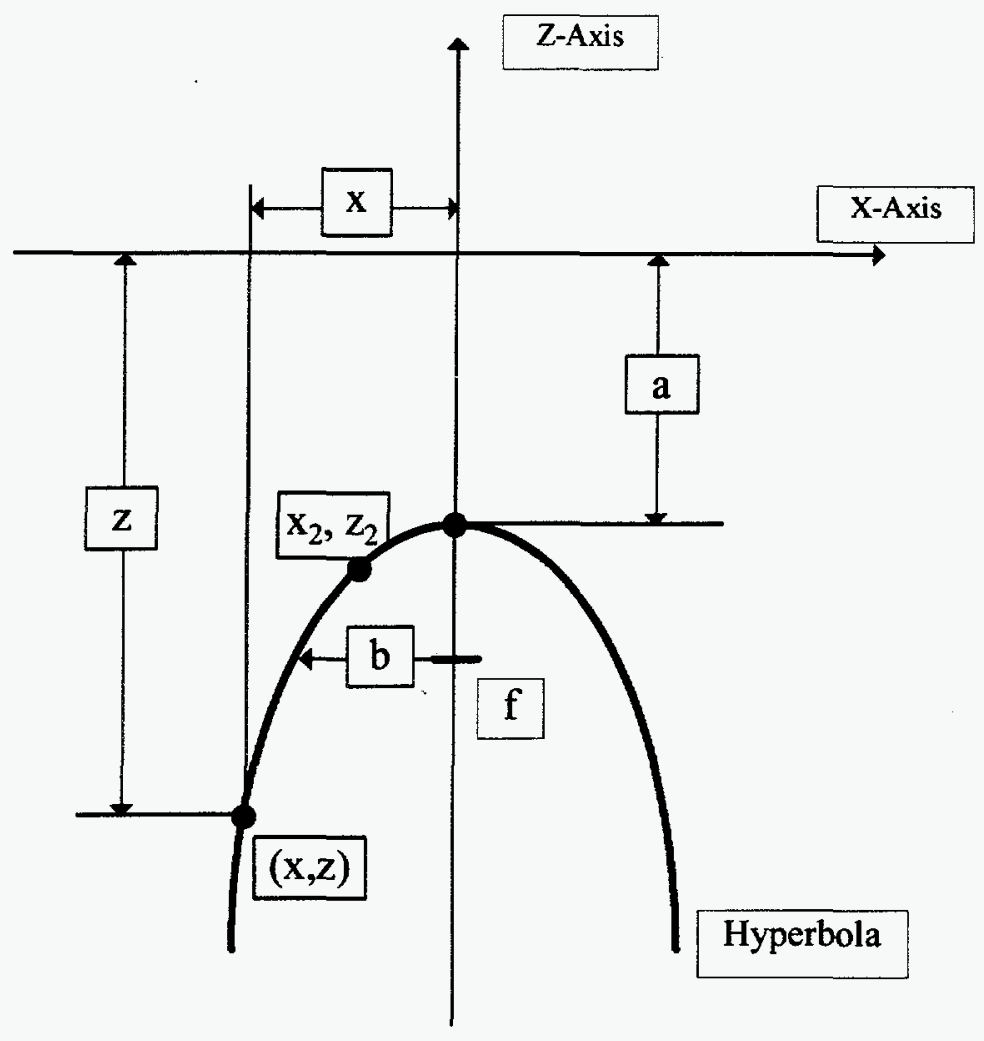

Figure 2: Description of Hyperbola

B. A more generic equation for any 2 points on the hyperbola is:

$$
e_{r}=\frac{x_{2}{ }^{2}}{\frac{\left[z^{2} \underline{x}_{2}{ }^{2}-z_{2}{ }^{2} \underline{x}^{2}\right]+x_{2}{ }^{2}}{\left[z_{2}{ }^{2}-z^{2}\right]}}
$$

C. The equations just developed are for the average value of $e_{r}$ in which the point target is embedded. For situations where different strata are encountered, a more complex equation can be developed that makes use of more data points to determine the different dielectric constant, and width, of each strata. Another option (if the strata are wide enough) is to use a point target located in the first strata and determine the dielectric constant for the first strata. Then using this knowledge, move down to the next strata and analyze a point target response located there, etc.

D. If a value for the dielectric constant (relative permittivity) can be determined, then it may be possible to identify and trace the extent of the subsurface material to be excavated. Prior knowledge of the geology of 
the area can be correlated with the measurements of dielectric constant. It should be noted that the potentially varying water content of the subsurface material will complicate material identification, since this can cause the relative dielectric constant measurements to vary. Table 2 presents a limited list of materials and typical dielectric constants.

\begin{tabular}{|lc|}
\hline Material & Relative Dielectric Constant \\
Air & 1 \\
Freshwater Ice & 4 \\
Sandstone - dry & 4 \\
Granite - dry & 5 \\
Sandstone - wet & 6 \\
Shale - wet & 7 \\
Granite - wet & 7 \\
Limestone - dry & 7 \\
Limestone - wet & 8 \\
Clay - saturated & 10 \\
Sand - saturated & 30 \\
Water - pure & 81 \\
\hline
\end{tabular}

1. Table 2: Material Dielectric Constants

VI. Commercial GPR System Descriptions \& Field Test Data- Two commercial systems were field tested near Las Vegas, Nevada.

A. Geophysical Survey Systems, Inc. (GSSI) GPR -

1. A GSSI 500Mhz impulse GPR system with a broadbeam antenna was used to take a data scan over a site that was then excavated with a Vermeer T-655 Trencher. The predominate rock at this site was caliche, a crusted lime deposit. The surface was generally smooth/powdery, bare of vegetation, and dry.

As can be seen in Figure 3, a definite transition interface between sub-surface rock conditions is evident approximately halfway down in the image. The depth of this interface is on the order of 3-4 feet. As the transition interface is followed across the image, it disappears to reappear a few feet farther on. When the excavator was run over this site, the area without a clearly defined transition interface was 'softer' and production was better than on either side, where the transition interface is visible. Excavator instrumentation to measure mechanical torque on the chain also indicated a difference in rock cutting production rate. Knowledge of where soft vs. hard rock is located can allow the machine operator to slow down when approaching hard rock and avoid over-stressing the Trencher. It can allow for a smoother transition into a different material. 


\begin{tabular}{|l|}
\hline X-Axis: \\
Direction of \\
Travel of GPR \\
over Surface \\
$(\sim 60 \mathrm{ft})$
\end{tabular}

$$
(\sim 60 \mathrm{ft})
$$

Surface of Ground

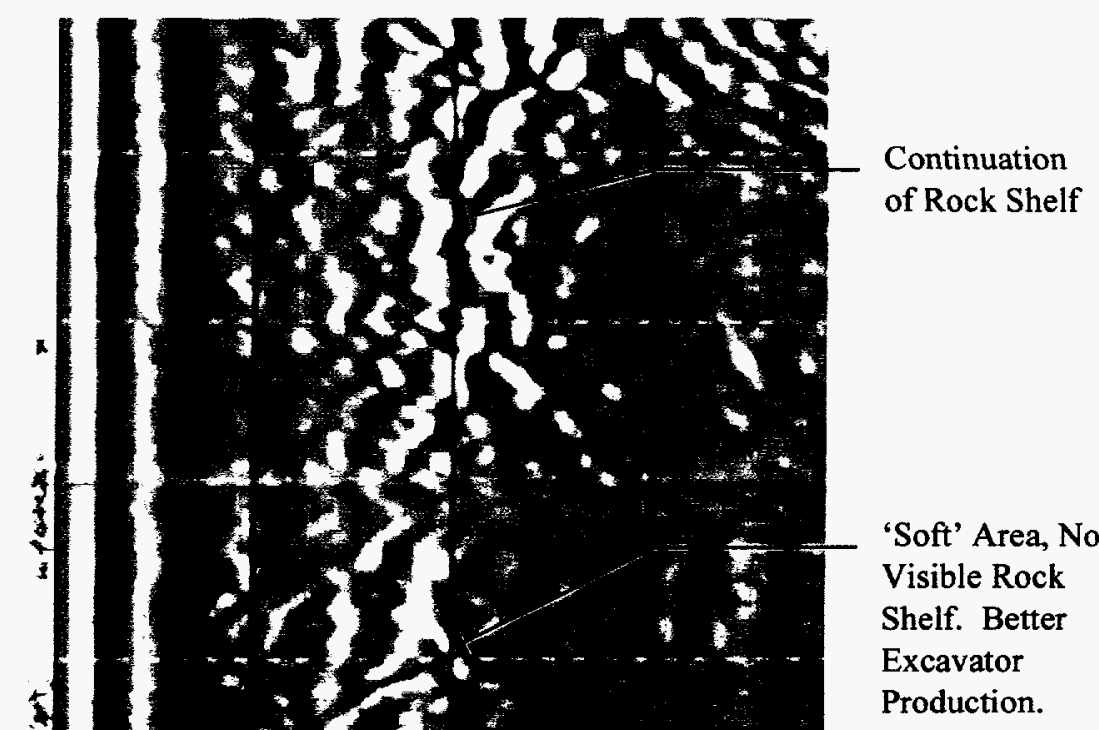

Desending

Rock Interface

Figure 3: GSSI - GPR Data 
2. The dielectric constant of the material can be estimated from a hyperbola point target response in the center portion of the image in Figure 3:

$$
\begin{aligned}
& x_{m}=2.63 \mathrm{ft} . \\
& z_{m}=11.38 \mathrm{ft} . \\
& a_{m}=8.31 \mathrm{ft} . \\
& \text { so: } \quad e_{r}=\left(11.38^{2}-8.31^{2}\right) / 2.63^{2}=8.7
\end{aligned}
$$

3. The GSSI unit could also detect buried pipes which were located at another site that had a pavement surface, see Figure 4. Because of the broad beam antenna used by GSSI, the image produced from reflection off a pipe appears as a downward oriented hyperbola.

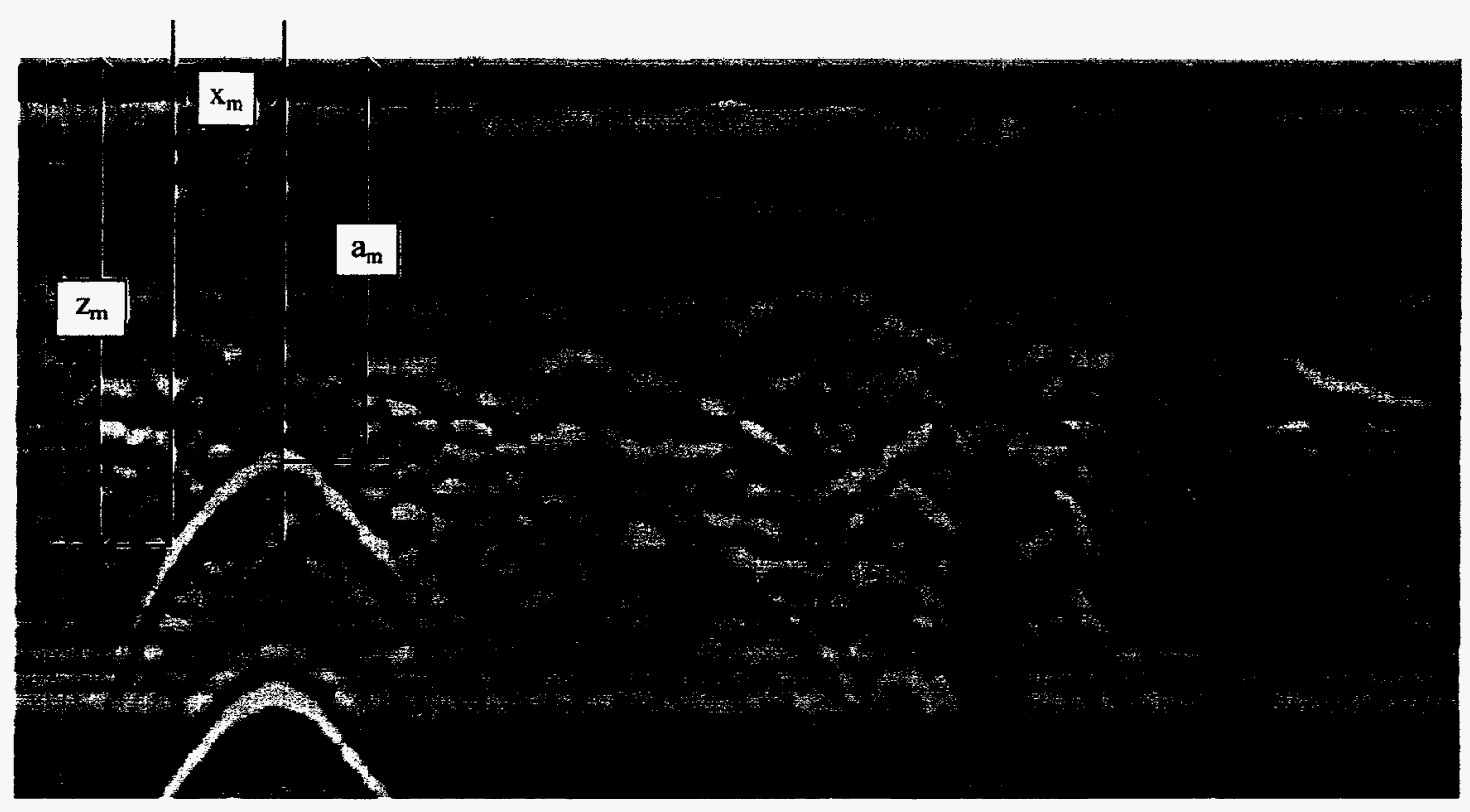

Figure 4: GSSI Scan over Pavement w/ Buried Objects (Pipes?)

4. In Figure 4, the estimated (average) dielectric constant $\left(e_{r}\right)$ above the selected hyperbola is:

$$
\begin{aligned}
& x_{m}=3.3 \mathrm{ft} . \\
& z_{m}=12.8 \mathrm{ft} . \\
& a_{m}=10.6 \mathrm{ft} . \\
& \text { so: } \quad e_{r}=\left(12.8^{2}-10.6^{2}\right) / 3.3^{2}=4.7
\end{aligned}
$$


B. A Sensors \& Software Inc. 450Mhz impulse GPR system with a broadbeam antenna was used to collect data at a paved site. Figure 5 presents a GPR wiggle-trace image of this data and shows a partial hyperbola representing a target such as a pipe about two-thirds of the way down in the image (Z-axis). The Sensors \& Software GPR also uses broad-beam antenna's.

From the GPR image it can be seen that there are different sub-surface reflection characteristics in the first half of the image vs. the last half (Xaxis). The last half of the image may indicate a more homogeneous material which would have fewer reflection interfaces than the material of the first part of the image. Another possibility is that the surface material is more conductive preventing penetration of the radar signal.

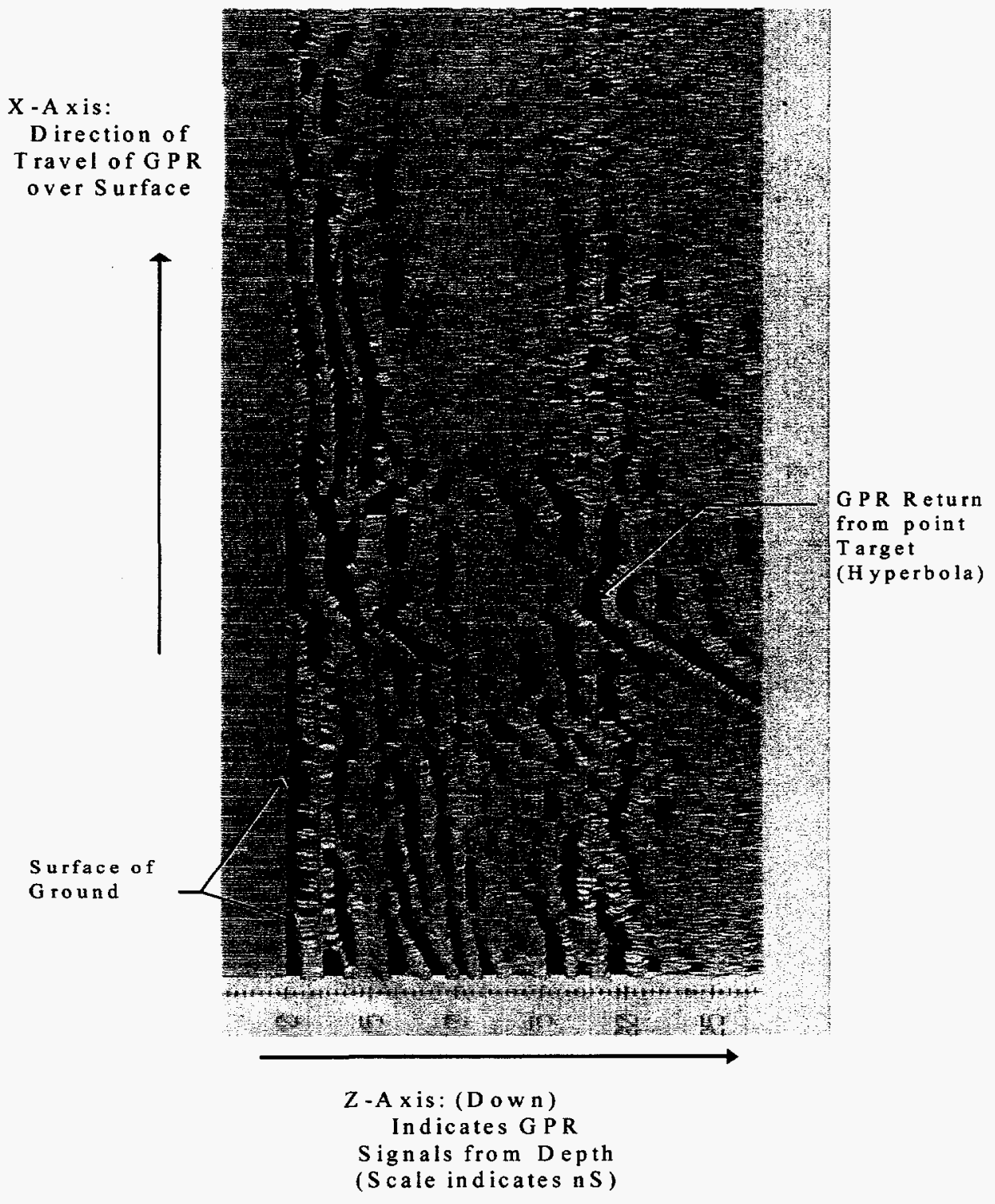

Figure 5: Sensors \& Software, Inc. - GPR Data 
VII. KCP GPR System Description-

\section{A. Hardware Description-}

Block Diagram- A block diagram of the KCP GPR system is presented in Figure 6. The system is centered around a HP8753C RF Network Analyzer (NWA) instrument. The output from the NWA (port 1) is connected through a RF Amplifier to the Transmit Antenna. The output of the Receive Antenna is connected to the input of the NWA (port 2). The network analyzer is connected by a GPIB cable to a National Instruments GPIB-Serial translator box which in turn is connected to the serial input port of the Notebook Computer (9600 Baud). GPR data files can be copied to a 3.5" floppy disk. The antennas are log-spiral and circularly polarized (CW \& CCW).

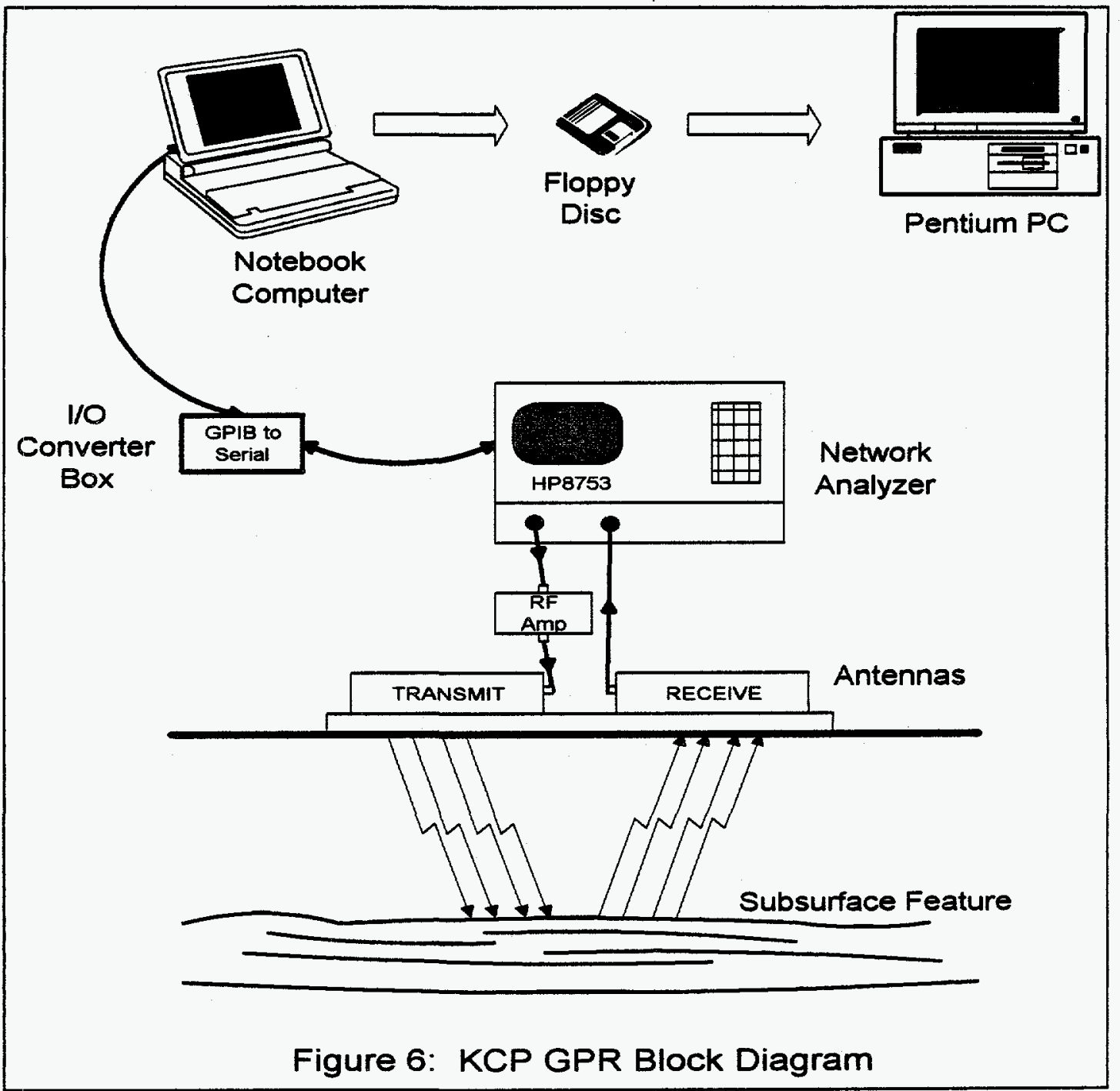


1. The NWA sweeps through a frequency bandwidth and makes signal measurements at selected frequencies through out the bandwidth. In TDR mode the NWA converts this frequency domain data into the time domain using z-transforms.

2. Table 3 presents a listing of the equipment used as a part of the KCP GPR system. Appendix B presents a photo of the system.

\begin{tabular}{|lll|}
\hline DESCRIPTION & SUPPLIER & PART NUMBER \\
Rf Network Analyzer (NWA) & Hewlett Packard & HP8753C \\
NWA Test Set & Hewlett Packard & HP85046A \\
Serial to GPIB Controller & National Instruments & GPIB-232CT-A \\
RF Amplifier, 3W (max) & EIN & Model 603L \\
RF Amplifier, 1/2 W (max) & Avantek & APG-2052 \\
RF Amplifier, 1/10 W (max) & Hewlett Packard & HP8347A \\
Notebook Computer & AST & Ascentia 900N \\
GPR Antenna \#1 & GeoRadar & CW Pol Log-Spiral \\
GPR Antenna \#2 & GeoRadar & CCW Pol Log-Spiral \\
Antenna Skid Plate \& Cart & GeoRadar & NA \\
Type-N Rf Cables & Pasternack & RG214 coax (or equi) \\
8HP, 115VAC Generator & Dayton & 4W108A \\
\hline
\end{tabular}

(a) Table 3: KCP GPR System

B. Software Description-

1. Executive Software Module-

The KCP GPR control software was written in MicroSoft Quick-C. The code is separated into 3 modules: GPR_EXEC.C (Executive functions), GPR_LIB.C (Library functions), GPR_DEF.H (Function \& variable definitions). The executable program file is GPR_EXEC.EXE. This program provides the operator with a system control menu. The software controls the setup of the network analyzer and prompts the operator through the instrument calibration. The operator has the capability to change the network analyzer settings if desired. Typically the Time Domain Reflection (TDR) mode is selected however frequency (FREQ) domain measurements can also be taken.

The operator can command the system to begin automatic collection of GPR data. The software then reads data from the network analyzer and stores it in an ASCII disk file (gprnnnnn.gpr). A BEEP sounds when it is time to move the 
GPR antenna's, approximately every 4 seconds. The operator can pause/resume/exit this automatic data collection or perform 'single-shot' TDR measurements. Note that TDR data (real number) are stored in one data file and FREQ data (complex number) are stored in $\mathbf{2}$ data files.

2. MATLAB Data Presentation / Analysis: TDR \& FreqResp-

The commercial program MATLAB was used to display the GPR data and perform analysis. The Network Analyzer TDR data can be displayed directly as a GPR image. The FREQ data must first be transformed using FFT or Z-transform functions into the time domain before display as a GPR image. (Most GPR images in this report were 'smoothed' using the 'shading interp' MATLAB command.)

C. KCP GPR System Parameters-

1. Network Analyzer Setup-

- $\quad$ Mode: S21

- Number of Points: 201, 401, or 801

- Averaging / Smoothing: No Averaging / 1\% Smoothing

- Calibration: Full 2-Port

- TDR Mode: BANDPASS

- TDR Format: LIN MAG (Magnitude of Reflection Coeff.)

- TDR Window: NORMAL (typical)

- TDR Gate: OFF

- TDR Span: 50nS (typical)

- $\quad$ FREQ Format: POLAR (if used)

2. HP8753 NWA TDR Characteristics-

- Maximum Unambiguous Range (RNG):

RNG = c * [(\#Points - 1) / FreqSpan $/$ Sqrt(Er)

\begin{tabular}{|c|c|c|}
\hline For: & $c=$ & $3.0 \mathrm{E}+08 \mathrm{~m} / \mathrm{s}$ \\
\hline & \#Points = & 401 \\
\hline & FreqSpan= & $\begin{array}{l}\text { StopFreq }- \text { StartFreq }= \\
1200-200=1000 \mathrm{Mhz}\end{array}$ \\
\hline & $\mathrm{Er}=$ & 3 (dielectric constant) \\
\hline & RNG = & $68 \mathrm{~m}(233 \mathrm{ft})$ \\
\hline
\end{tabular}


- Range Response Resolution ( or the capability to distinguish between 2 closely spaced targets):

$$
\begin{aligned}
R R R= & {[c * 1.2 *(1 / \text { FreqSpan }) * 1.6] / \text { Sqrt(Er) } } \\
& \text { ( for Bandpass, \& Normal Windowing ) }
\end{aligned}
$$

For above conditions -

$$
\begin{aligned}
& \text { RRR }=\quad 0.333 \mathrm{~m}(1.1 \mathrm{ft}) \\
& \text { Range Resolution : } \\
& \text { Rres = [ c * (TDR_Span) / \#Points ] } \\
& \text { For: TDR_Span }=\text { StopTime }- \text { StartTime = } \\
& \\
& \text { Rres }=\quad 0.037 \mathrm{~m}(0.123 \mathrm{ft})
\end{aligned}
$$

3. Bandwidth Tradeoff: $500 \mathrm{Mhz}$ vs $1 \mathrm{Ghz}$ vs $3 \mathrm{Ghz}$

Figure 7 illustrates how changing the received bandwidth (BW) affects the range response resolution. This data was taken with the antennas moved over a floor, under which was a basement room with pipes and air ducts. The scan transitions from the basement room to foundation fill dirt under the floor (on the right in the image).

The GeoRadar antennas used in the KCP GPR system are very narrow beamwidth in contrast with the commercial systems previously discussed. This is due to their design that makes use of a dielectric material in front of the antenna elements, which works to focus the radar beam. Thus images produced with the KCP GPR system will not have the hyperbola response characterized by a point target as in the commercial systems.

The GPR bandwidth was reduced from $3 \mathrm{Ghz}$ to $1 \mathrm{Ghz}$ then to $500 \mathrm{Mhz}$ on different scans of the site. The $3 \mathrm{Ghz} B W$ start frequency was $300 \mathrm{Khz}$ and $10 \mathrm{Mhz}$ was used for the other two BW's. Note that as the $B W$ is reduced, more power is concentrated at lower frequencies.

At $3 \mathrm{Ghz} B W$, features of the floor over the basement are fairly well resolved in comparison with the 500Mhz BW case. In all 3 cases the transition from the basement room to the fill dirt is identifiable on the right side of the image. The metal air duct on the left, at a depth of about 9 feet provides a good reference for illustrating the affect of the changing resolution of the system. At $3 G$ hz the duct is well resolved however effects of the antenna mismatch produce multipath images for the surface of the duct. As the BW is reduced the antenna mismatch improves and the multiple images disappear, however the resolution of the duct surface begins to degrade. 
The $1 \mathrm{Ghz} \mathrm{BW}$ seems to produce an image that best resolves the metal duct with minimum of distortion. Features can also be seen in the foundation fill region. The $500 \mathrm{Mhz} B W$ seems to penetrate the surface better that the wider BW's, however it is only able to resolve larger target features.

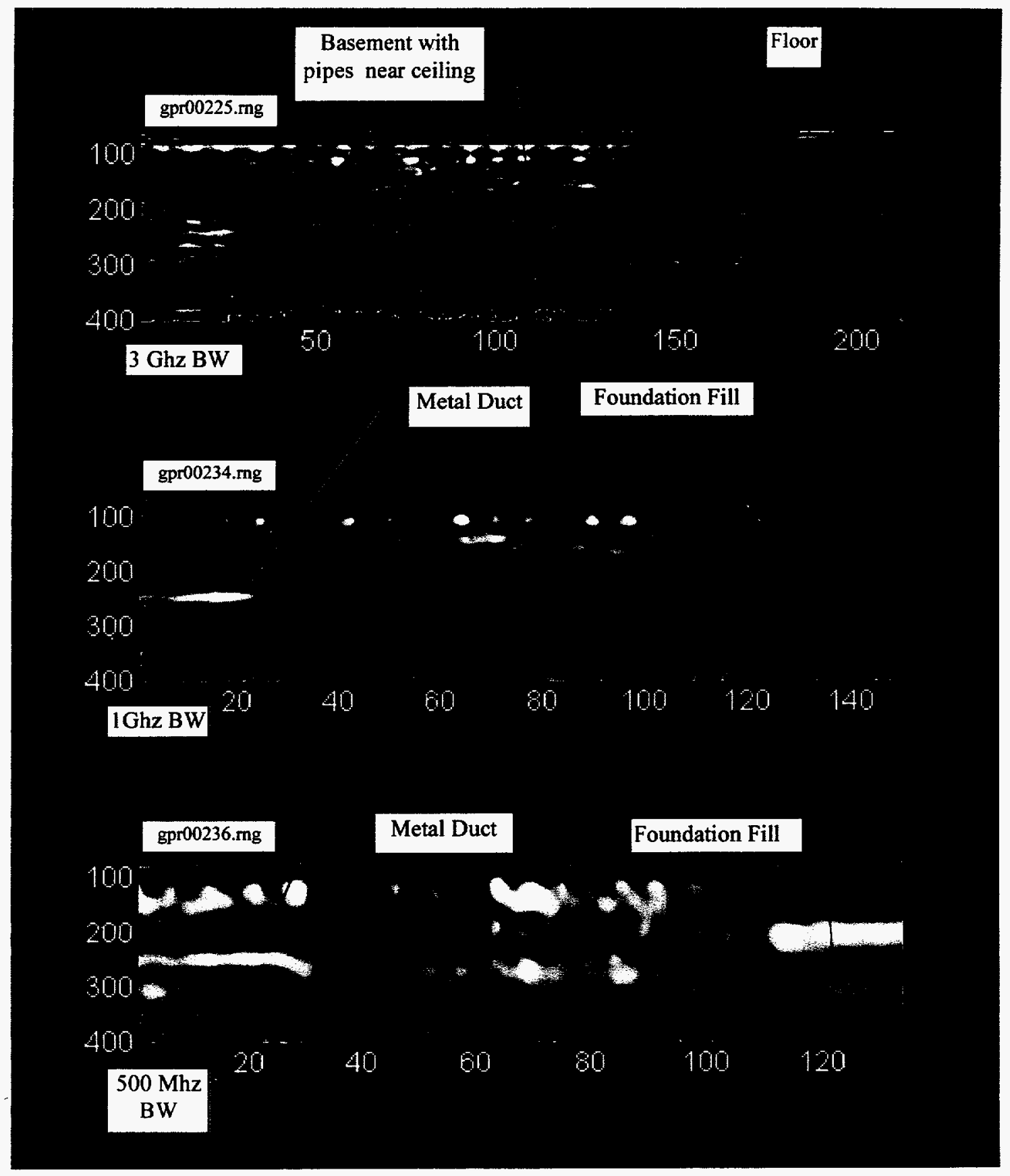

Figure 7: Effect of Decreasing Bandwidth on GPR Image 
VIII. Impulse vs. Swept Frequency GPR-

A. Impulse GPR's typically emit a single sinewave monocycle into antennas that are tuned for the sinewave frequency. Reflection signals in the time domain are received and processed based on time of arrival. Swept frequency GPR's emit a series of frequencies over a wide bandwidth into a broadband antenna. The receiver makes measurements of received signals at each of the transmitted frequencies, and this data is processed to convert it from the frequency domain into the time domain to produce time of arrival results.

B. The impulse GPR can have major distortions especially in the "first sinewave depth" due to the antenna response (ringing). A swept frequency GPR can also have distortions due to antenna mismatches especially at the higher frequencies. However, by it's nature this antenna is a better match. In both types of systems the distortions are magnified if the antennas do not make good contact with the ground.

C. One method of improving the GPR image of near-surface objects is to pull the antenna back away from the surface by placing a "dielectric spacer" between the antenna and surface. This "spacer" provides a better match for the antenna impedance reducing the mismatch ringing. This also physically increases the range to the near-surface target which moves it's reflection signals out in range 'away' from the primary near-in antenna distortions. It should be noted that the distortions due to the antennas will have some affect on reflections from all ranges.

IX. RF Output Power-

A. In the early stages of this experiment it was found necessary to add an RF amplifier in the transmit path. The HP8753 Network Analyzer has good dynamic range, however, to reduce the noise level it would be necessary to use a large number of averages. Since the analyzer is relatively slow in taking measurements, this would have greatly increased the time needed to take data. Additionally, some target site surface and sub-surface conditions prevented good coupling and transmission of the GPR signal into the ground and thus higher power was required. Even though the $\mathrm{S} / \mathrm{N}$ is much improved using the amplifier, the received signal strength from a typical subsurface feature is still a small value, on the order of 0.010 reflection coefficient or $40 \mathrm{~dB}$ return loss. 
B. An RF power amplifier was used on the GPR transmit side to compensate for the high power loss through the antennas, and because of the attenuation loss of the subsurface media. Figure 8 presents images that show the effect of increased transmitted power over the same target site, having a relatively smooth surface and buried metal pipe. The image on the right was taken with $6 \mathrm{~dB}$ increased transmit power. It is apparent that the targets are brighter in the second image and that more subsurface detail is visible before and after the targets.

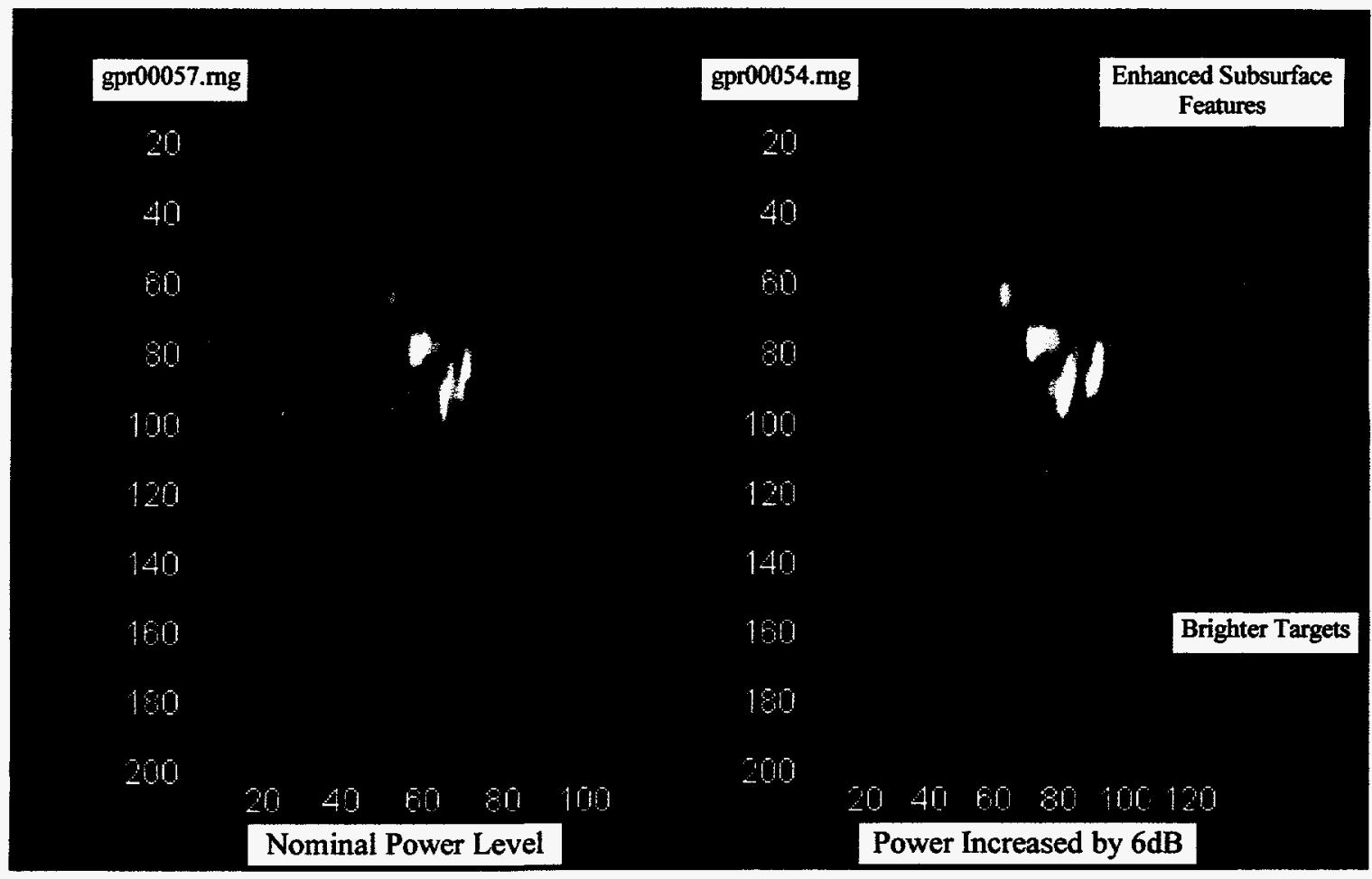

Figure 8: Effect of 6dB Increase in GPR Transmit Power

X. Antenna Effects-

A. Polarization -

1. Orthogonal polarization's can be used for transmit and receive antenna's to reduce direct antenna-to-antenna coupling. This can also enhance returns from pipes and subsurface planar interfaces as indicated in the literature research.

2. The GeoRadar antennas used in the KCP GPR experiments were Clockwise (CW) and Counter-Clockwise (CCW) circularly polarized, respectively. The polarization angle rotates with the frequency sweep rate of the Network Analyzer. Thus each frequency in the sweep has a unique polarization orientation. 
3. Fixed linearly polarized antennas maintain a constant, nonrotating, linear polarization. For some depths, circularly polarized antenna's may detect pipes in any orientation where fixed polarization antennas may not.

B. Wide Beam vs. Narrow Beam: Hyperbola vs. Resolved 'Image' -

1. A "wide" beamwidth antenna produces a hyperbola in the image of a point target because the buried target (pipe) reflects some energy back to the GPR even when the antenna is still some distance away from being directly over the target. The returns are also at a further (slant) range and thus the target appears deeper. As the antenna is moved over the target, the energy is reflected straight back up to the GPR from a minimum range. This produces the hyperbola in the GPR image. This is a potential problem when a number of point targets are in one area because the energy reflected off of these nearby objects can interfere with each other and distort the image.

2. A "narrow" beam antenna system can resolve point targets to a point image potentially giving a more representative image of the sub-surface target. However any 'noise' in the GPR system may also appear as a 'target' in the image, where as with the broad beam system a hyperbola is very indicative of a true sub-surface point target.

C. Direction of Antenna Travel Over Surface-

Polarization of the antenna vs. point targets (pipes) is a very important consideration. The GeoRadar antenna circular polarization orientation rotates with frequency sweep rate, whereas a GSSI or Sensors \& Software linear polarization antenna will keep the same POL orientation. Additionally, linear polarization antennas will maintain their POL orientation with depth or penetration, while GeoRadar antennas POL orientation will rotate improving detection of randomly oriented targets.

However, even though the swept frequency produces a circular polarization that rotates with the frequency sweep rate, as the signal propagates through the ground the lower frequency's are selected (higher frequencies are attenuated) and thus the polarization will be less circular and more linear at greater depths. This means that the strength of target reflection off of any polarization sensitive target at depth will still be dependent on the orientation of the antenna at the surface.

Antenna orientation can also be an issue when using dual antenna systems (separate transmit/receive antenna's). If the antenna's are drug over the ground one behind the other then the front antenna may be over one type of medium while the rear antenna is over a different type. This situation could also occur if the antenna's are oriented in a side-byside configuration. For 'extended targets' like rock shelf's, this may not cause a problem. However if 'point targets' like pipes are encountered, the orientation of the antenna's over the pipe could determine if it is 
detected or not, especially if using narrow beam antennas. (NOTESide by side antenna orientation may work better).

1. Figure 9 provides an illustration of the importance of antenna orientation with respect to a buried target such as a pipe. Figure $9 a$ is data from the site with the transmit antenna in front of the receive antenna. Figure $9 b$ is GPR data from a pass over the same site with the antennas in a side-by-side configuration. The pipe is readily visible in the data of Figure $9 \mathrm{~b}$ at Z-index 160. However, no clearly visible return from the pipe is seen in Figure 9a. In the side-by-side configuration, the antennas are aligned parallel with the pipe.

Figure 9 - KCD GPR Data From Buried Pipe at $\sim 8 \mathrm{ft} @ \mathrm{MSB} / \mathrm{TTC}$

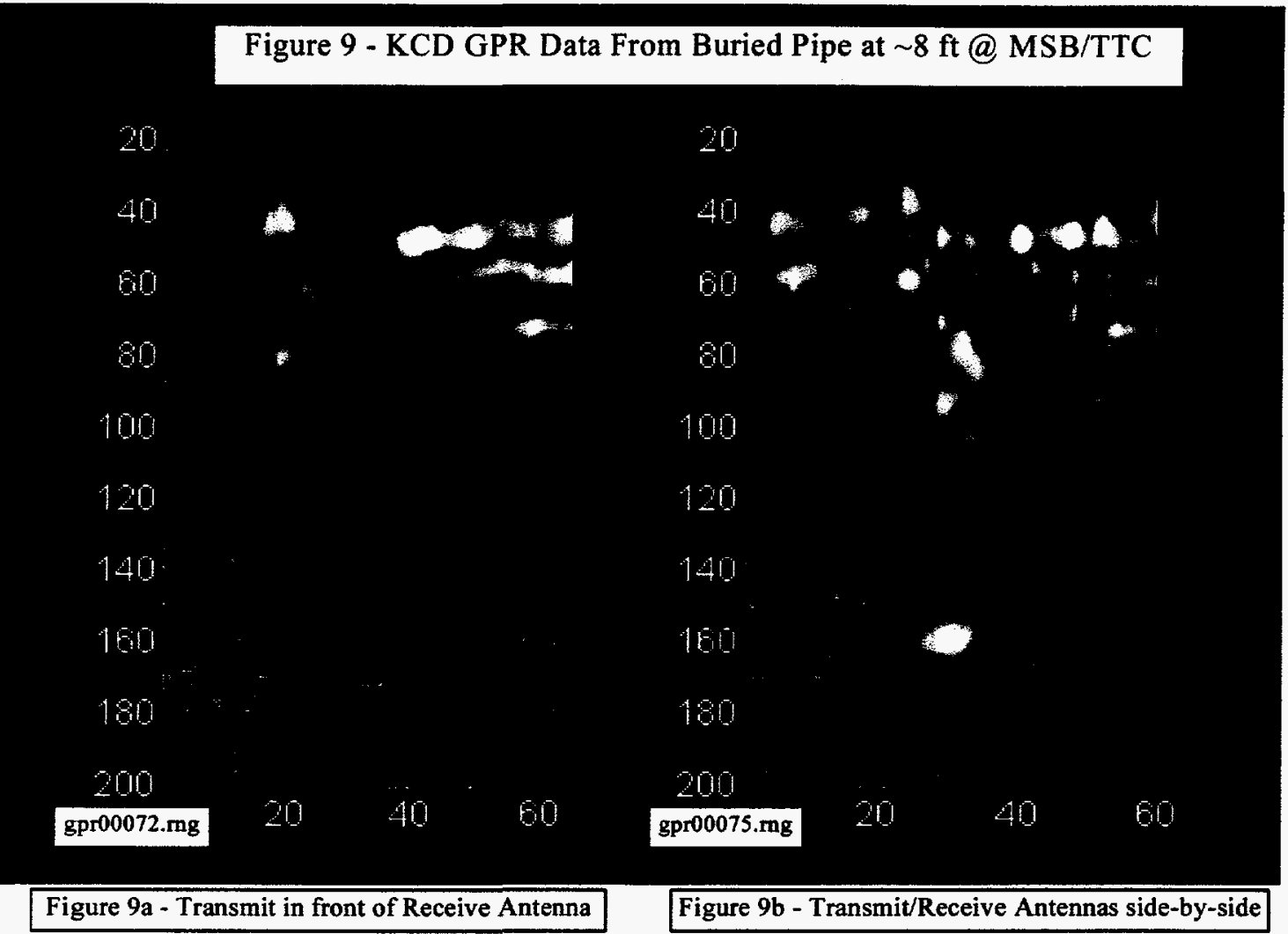

2. In Figure 10 two different antenna orientations are used in two separate scans over the surface of the floor inside a building. The scans start over a concrete slab that is on top of foundation fill dirt then transitions (at sample number 21) to a floor over a basement. In the top image the antennas were drug over the floor with the receive antenna following the transmit antenna. The bottom image was taken with the transmit and receive antennas side-by-side. A wide bandwidth of $\sim 3 \mathrm{Ghz}$ was used to provide a good range response resolution. 
The bottom image clearly indicates the re-enforced structure of the floor over the basement, whereas the top image shows little indication of this structure.

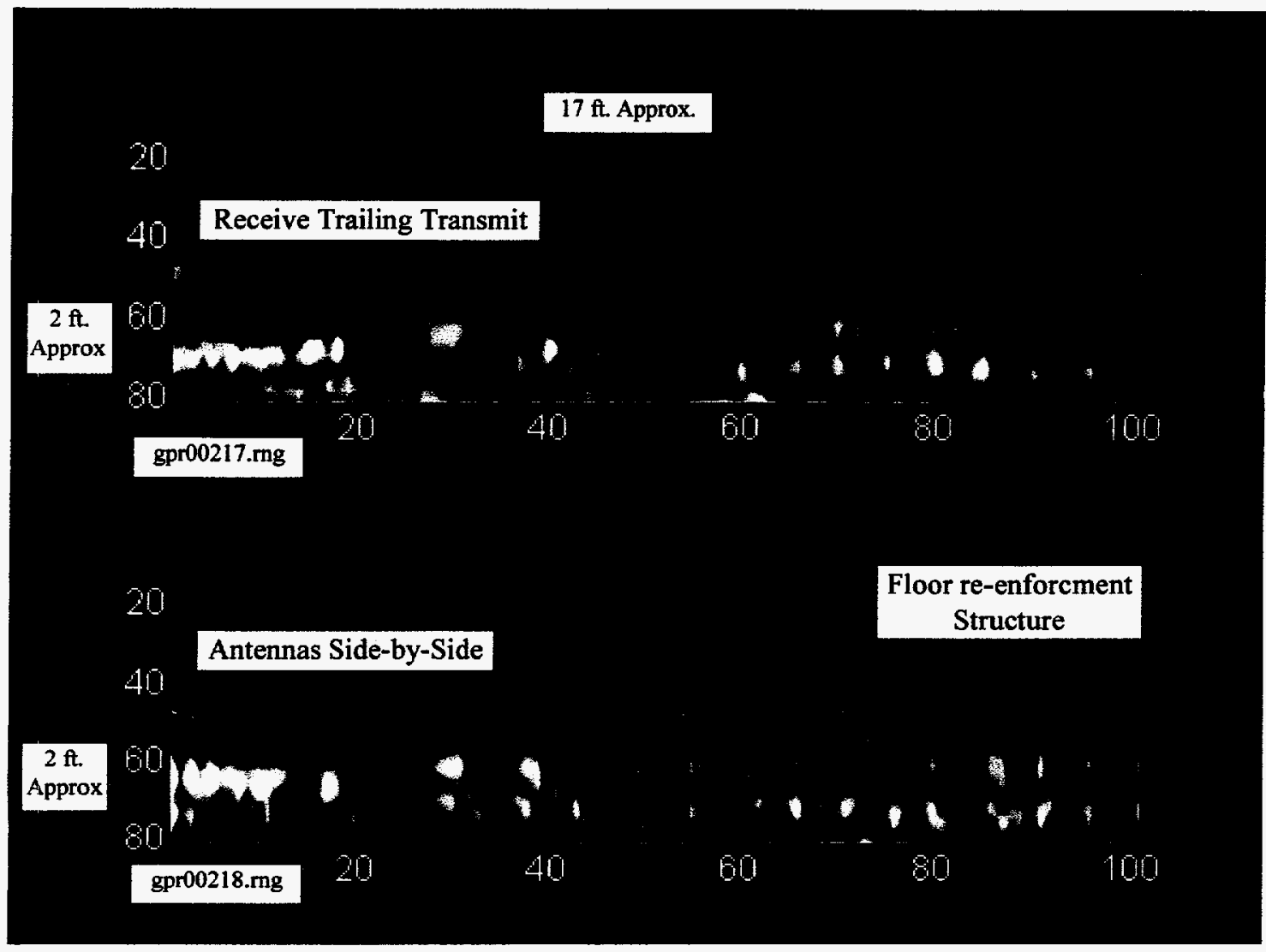

Figure 10: Antenna Orientation Effects on Floor Scan

XI. Data Processing-

A number of data processing techniques were used in the analysis of GPR data. These techniques include pre-scaling the raw GPR data using a gain factor that increases with time (range), processing an image to remove trends, and use of different pre-FFT windowing functions.

A. The time dependent gain, or sensitivity time control (STC), reduces the amplitude of close in signals and increases the amplitude of signals from greater depths. Since the initial ground surface return as well as direct antenna - to - antenna coupling are so large, they can dominate in an image produced using the raw GPR data. This is OK if the near surface features are the targets of interest. However if deeper probing is required it is generally necessary to apply some type of STC to the raw data prior to displaying it as a GPR image.

After some experimentation, a STC gain that increases linearly with increasing range (time) was used. This gain enhanced target images at the lower depths while retaining acceptable information about the 
surface reflections. Three C-programs (gpr2loss.exe, gpr4loss.exe, \& gpr8loss.exe) were written and used depending on the number of points collected. These programs read the raw data files (gprNNNNN.gpr), apply the STC gain and store the results in another file (gprNNNNN.rng).

Figure 11 illustrates the effects of applying the STC gain factor. The image of raw data, on the left, shows good detail of near surface features of the site. The scan is over a gravel area that transitions to pavement. The image on the right show the effect of applying the STC gain to the raw data. Now a pipe is visible at a depth of about $6 \mathrm{ft}$, which was not visible in the first image. Surface features are still visible.

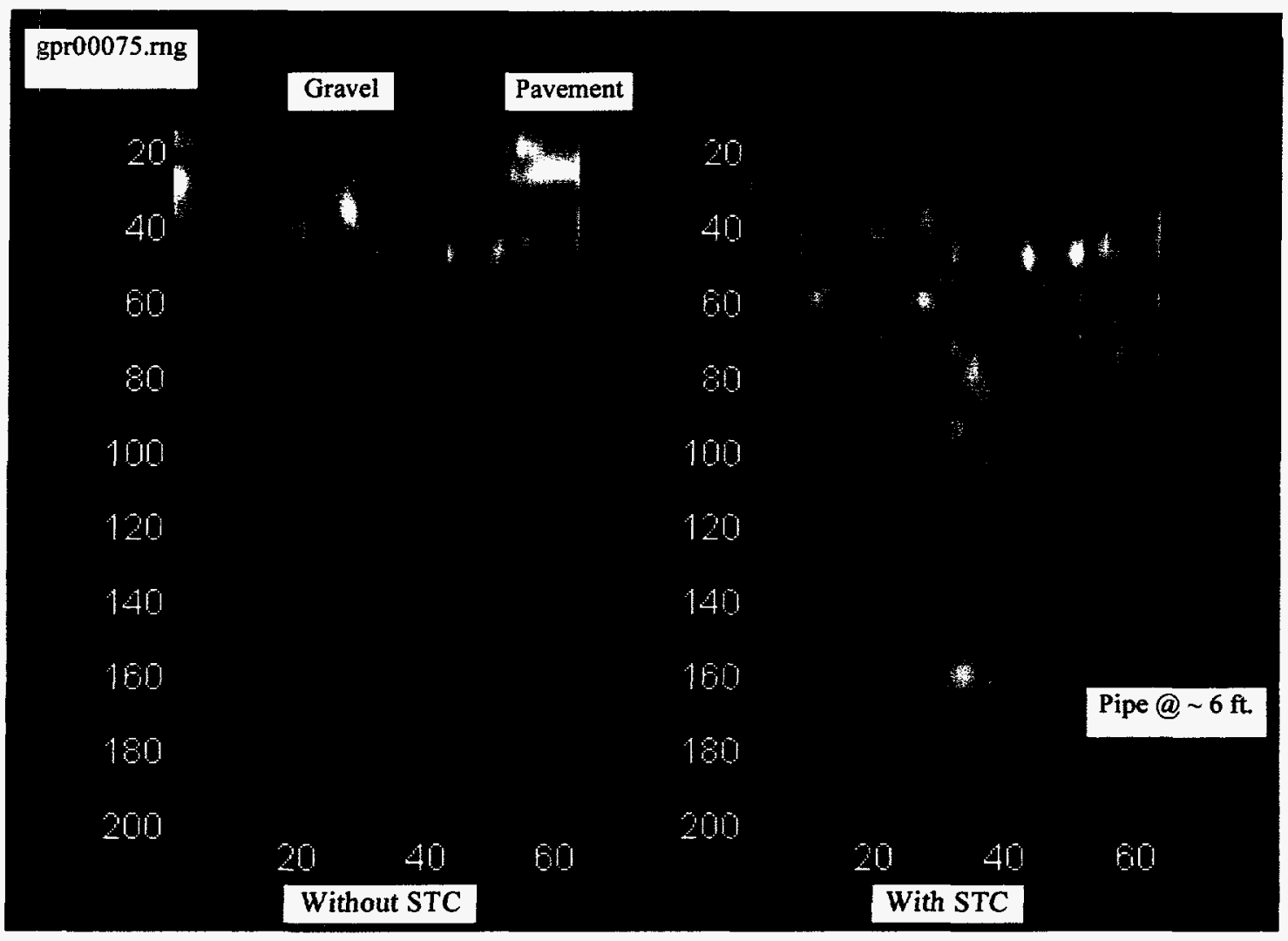

Figure 11: Effect of Using STC Gain

B. The use of the MATLAB function 'detrend' removes the mean value or linear trend from a column of a matrix. Detrend can be used to process the GPR images (either raw or STC compensated) to remove or reduce the effects of consistent antenna pattern distortions, surface reflections, and consistent subsurface features such as planar rock interfaces. As a result, point targets such as pipes or fractured rock chunks tend to be highlighted by this process. The down side is that this detrend process can reduce signal returns from planar rock shelf interfaces, which are of interest in this project. However, if the 'direction' of the detrend is controlled, ie- detrend in depth vs. along track, planar interface information can be preserved in the image. 
Figure 12 shows effects of detrending in depth and along track, on STC compensated GPR data.

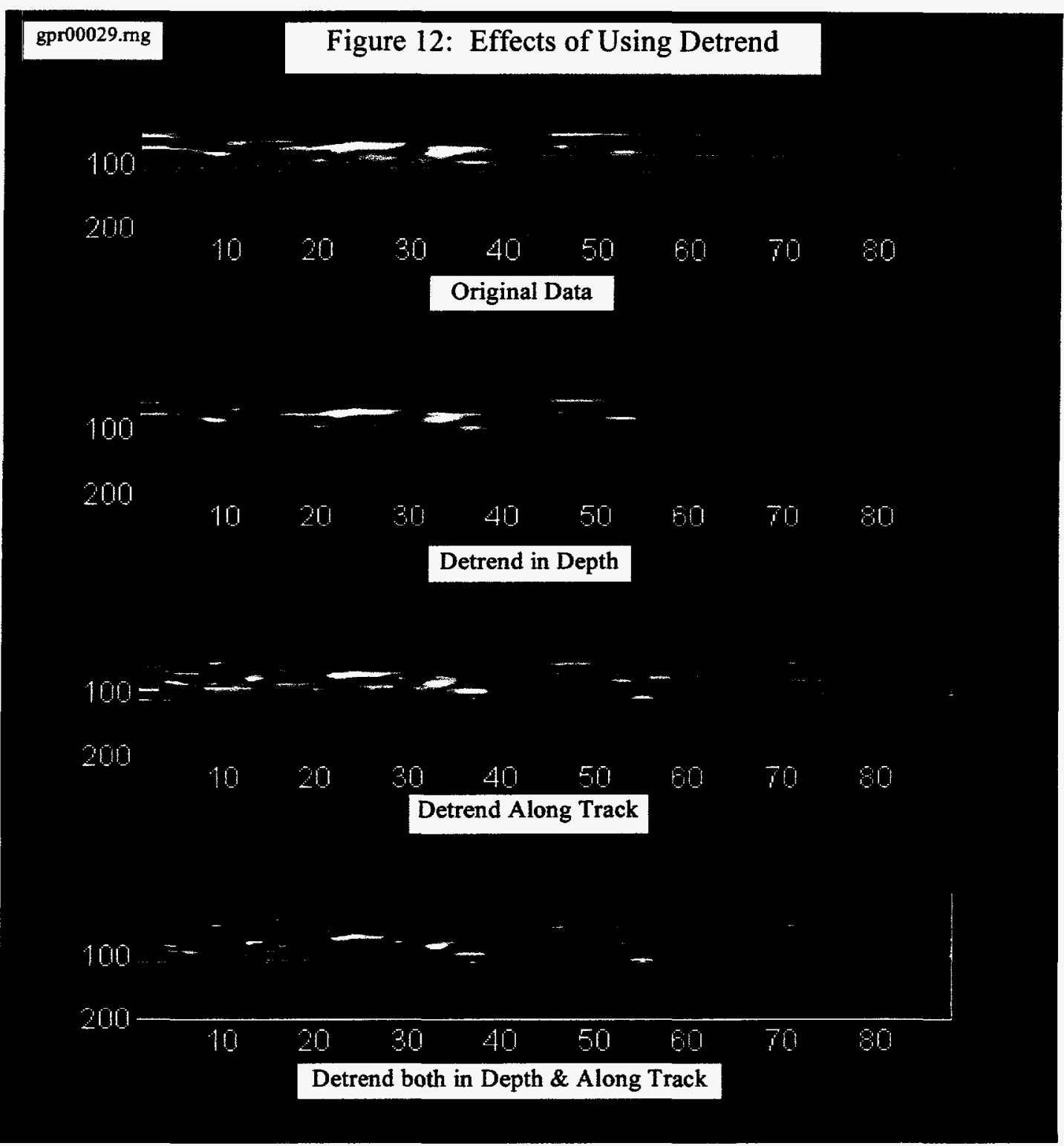

C. Inverse FFT Processing: Pre-windowing of the frequency domain data is critical to producing useful images. Performing inverse FFT on unwindowed raw data will produce images with distortions because of the truncation of the data sequence. 
To investigate the effects of changing the pre-FFT window width, the Network Analyzer relative window width was changed from Wide to Nominal to Narrow. Three GPR scans were taken over the same target site. The site had sub-surface features that included a concrete surface over earth fill then transition to a basement room with metal pipes and ductwork just below the basement ceiling. As can be seen in Figure 13, the Wide window produced good resolution of the basement ceiling floor and metal ductwork, and even indicated a return from the basement floor. As the window width is made smaller, from a nominal width to the narrow width, a better image of the transition from earth fill to the basement room (void) is produced. Smaller surface features aren't as well defined.

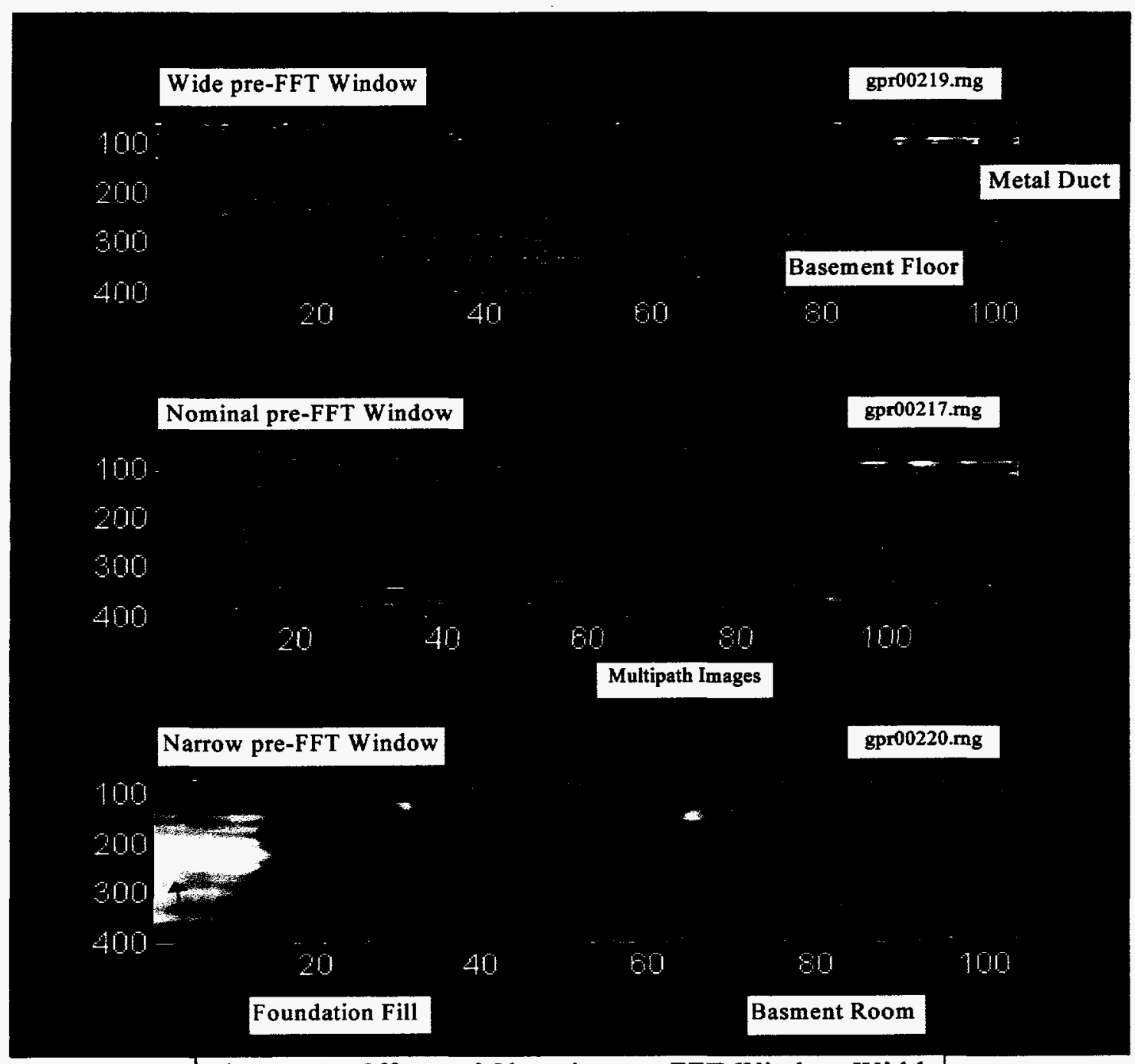

Figure 13: Effects of Changing pre-FFT Window Width 
XII. KCP Testing Results-

A. Transition from Homogeneous Subsurface to Disturbed Earth and VoidsFigures $7 \& 13$ present images that show good contrast in returns between earth and sub-surface voids. Additionally, Figures 8 \& 19 demonstrate how the GPR can distinguish between undisturbed earth (old road bed) and disturbed earth ( filled-trench ).

B. Near Reflector vs Far Reflector Effects- Highly reflective targets that are close to the surface will degrade returns from deeper targets because of multipath and because of a reduction in the transmitted signal strength. Figure 13 presents an example of how multipath clutter distortion can appear. Strong reflections from the floor and from metal ducts near the basement ceiling produce a large part of the clutter in this image.

C. Location and Tracing of 6" Pipe in Soil @ 4 ft depth- This site (Figure 14) was at a gravel road that had at one time been trenched across to bury a 6 inch metal water main. Three separate parallel GPR scans were taken along the road path, but with the same start and stop lines. Scan \#1 was taken over a very smooth portion of the gravel road. Scan \#2 was taken -1.5 feet from Scan \#1 and Scan \#3 was taken $~ 4$ feet from Scan \#1. Figure 14 shows that the pipe did not transition perpendicular to the road but was laid in at an angle to the road, which facilities maps confirm. Note the increase in 'clutter' in Scan's 2 \& 3 due to rougher surfaces. Scan's \#1 \& \#2 indicate a fairly clear transition from old road bed to disturbed earth (trench).

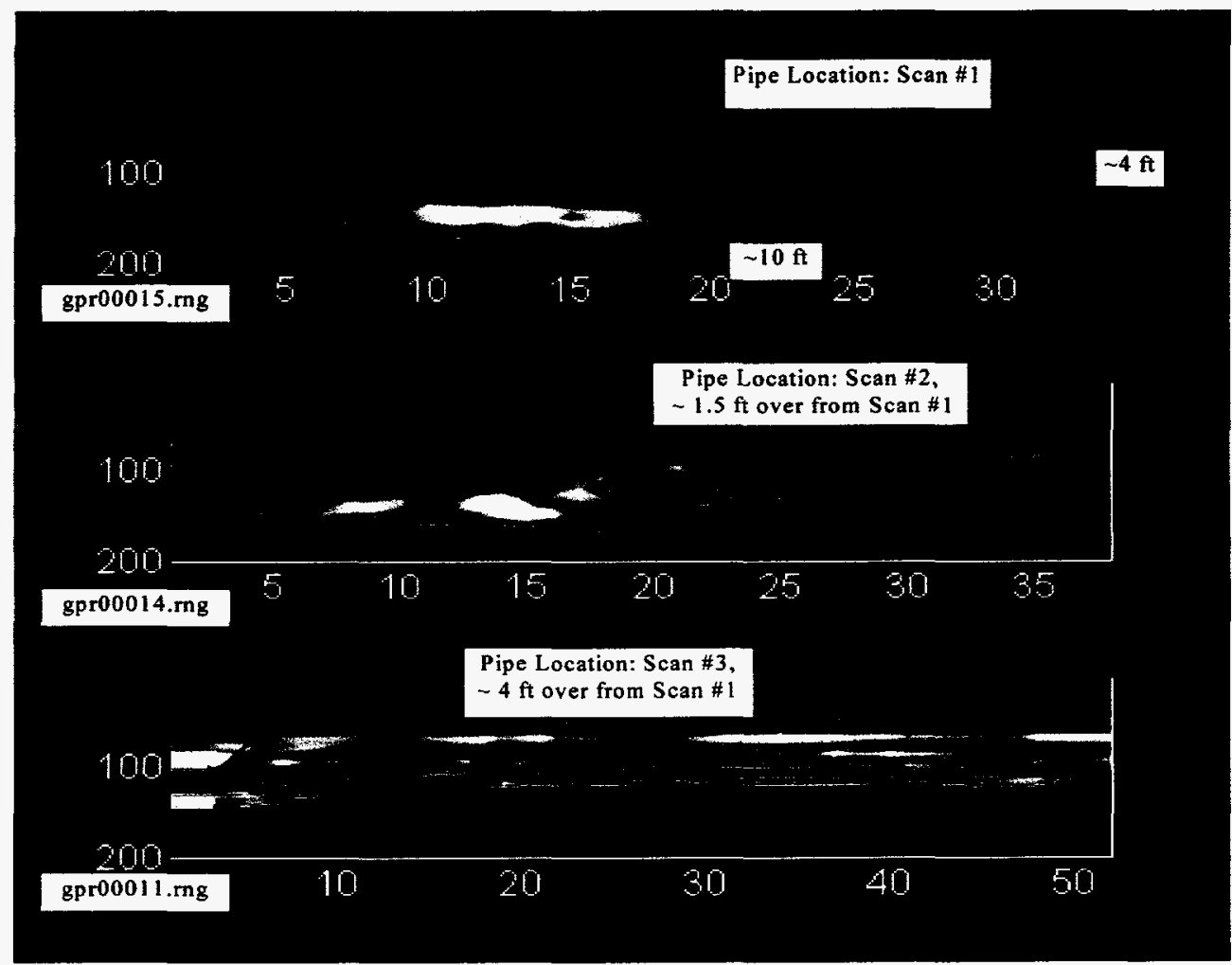

Figure 14: Parallel GPR Scans Across a Buried Pipe Trace 
D. Smith Farm Field Test Results-

A GPR scan was taken in a pasture over a subsurface rock shelf that ends abruptly due to erosion in a stream bed. The surface conditions are not very favorable, having lots of thick grass. Images of this site were generally poor because of the severe mismatch at the surface due to the grass, however a contour plot of the data shown in Figure 15 does indicate a transition interface between the rock shelf zone and the disturbed erosion deposits. These findings were confirmed by digging test holes into the ground.

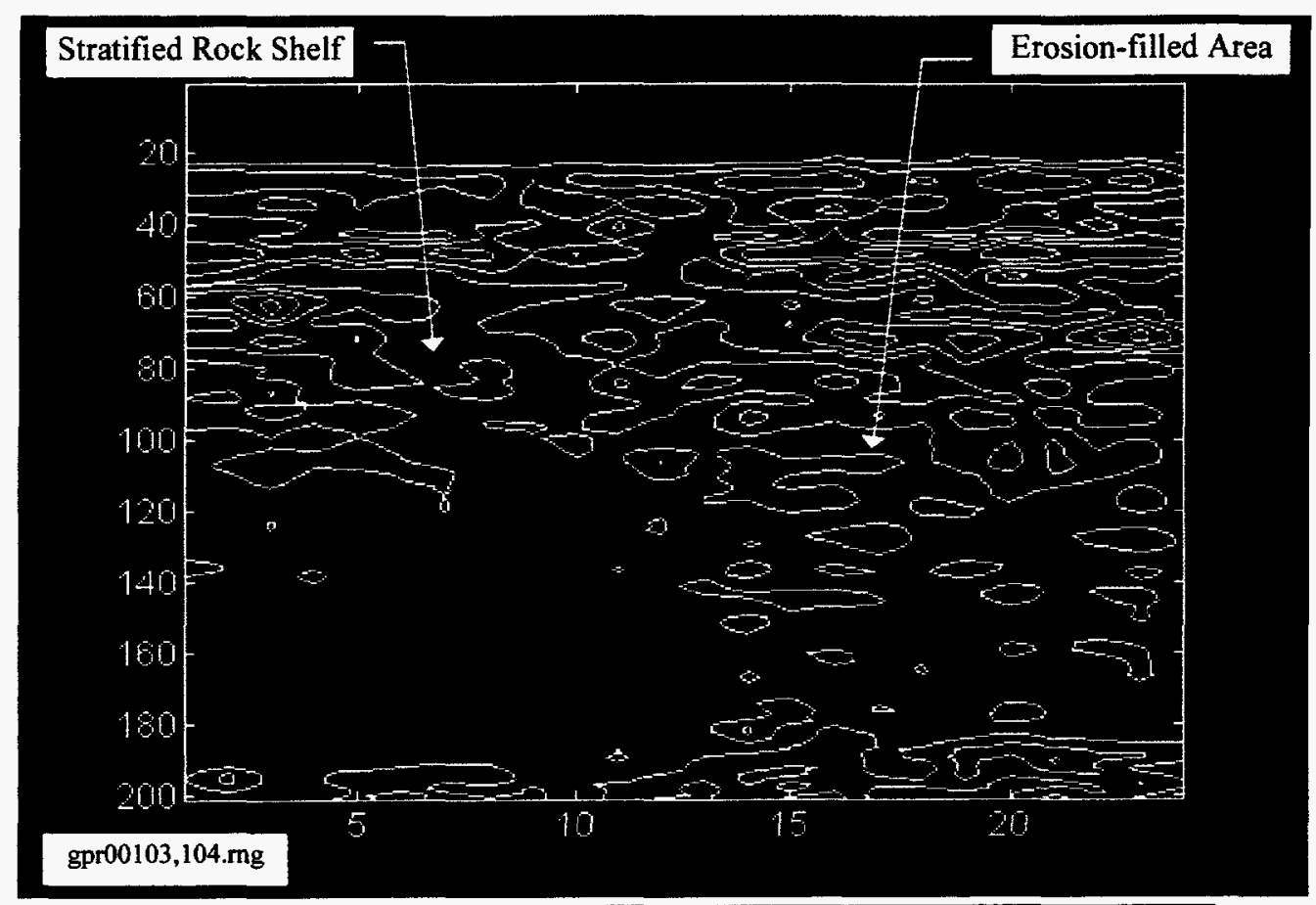

FIGURE 15: Smith Farms Remote Site- Rock Shelf Contour 
E. Bannister Rd/ Highway 71 Field Testing Results-

Figure 16 presents the GPR image of this site. The site had a relatively smooth rock/gravel surface with minimal vegetation. The GPR bandwidth was set at $\sim 3 G h z$ to provide maximum resolution. A surface rock outcropping is visible in the image.

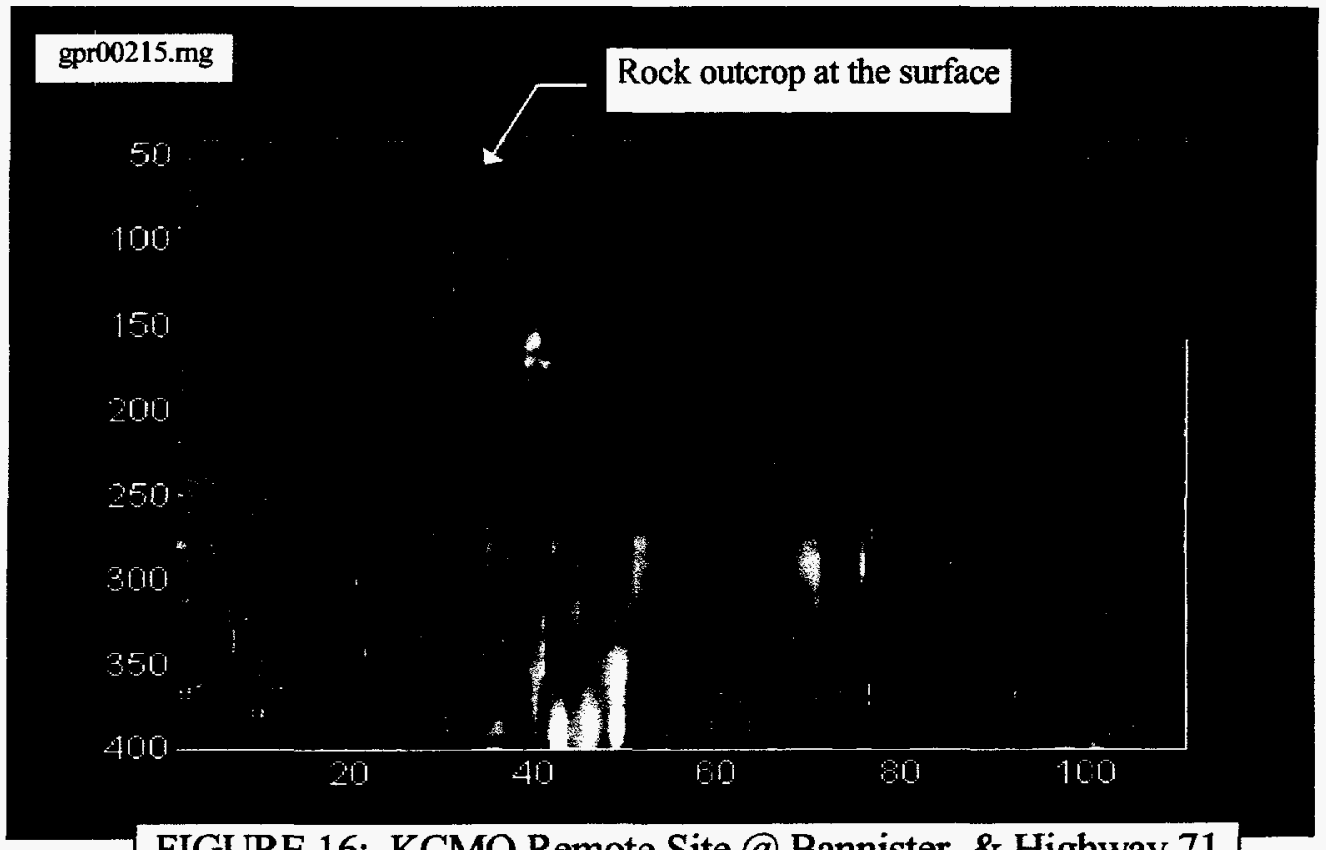

FIGURE 16: KCMO Remote Site @ Bannister \& Highway 71

Use of varied video colormaps can be used to enhance different features of the GPR images. Figure 17 presents the same data as in Figure 16 in a different color scheme and includes a signal intensity contour overlay.

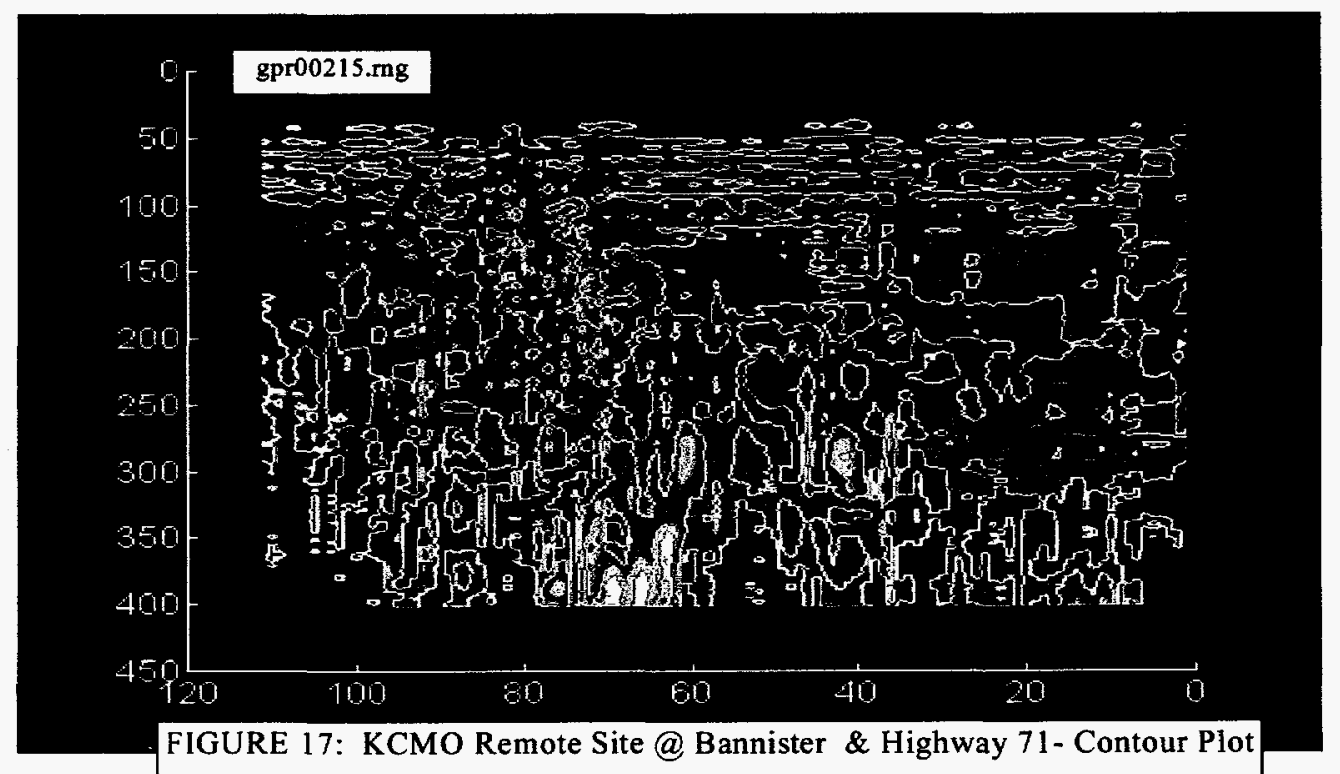


XIII. Environment Description-

A. Sub-surface 'target' characteristics-

Point targets can be harder to identify than planar interfaces (rock shelfs) using the KCP narrow-beamwidth GPR system. Planar surfaces will have a general trend through the data image, whereas point targets will be isolated 'bright' spots. These 'bright' spots could be pipes or they could be isolated rocks or they could be GPR system errors or even multipath signals. An advantage of the broad beamwidth systems may be that point target returns could at least be distinguished from GPR system errors since point target signals would exhibit the characteristic hyperbola signature whereas system errors typically would not.

B. RF Penetration Depth vs Frequency -

Since not all of the frequencies penetrate to the lower depths, the effective frequency span (bandwidth) is reduced, resulting in less range response resolution at the lower depths.

C. Surface Effects-

GPR images can be distorted by surface roughness, grass, airgaps, and near-surface reflectors (rebar, etc.). These surface conditions can affect all depth cells, masking good retums and reducing the dynamic range of the GPR. In the case of rebar, the lower RF frequencies will be filtered out thus reducing the range of the GPR since the lower frequencies tend to travel with less attenuation through the earth. 
1. Figure 18 shows the increased distortion in the GPR image when going from a relatively smooth surface to a more rough surface with some vegetation.

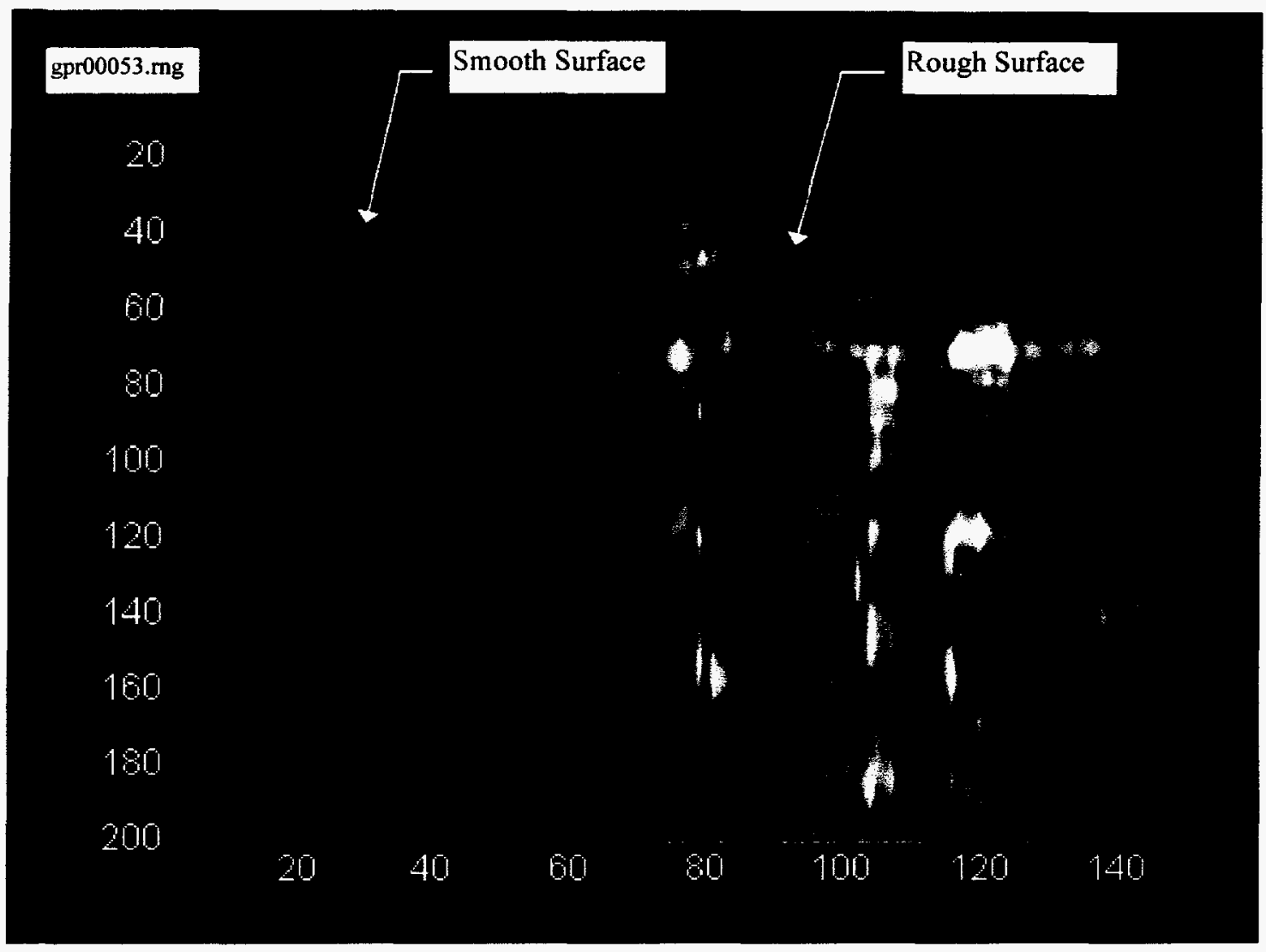

Figure 18: Transition from Smooth Surface to Rough 
2. Figure 19 shows the effect on the GPR image of a buried pipe in a filled-trench due to different surface roughness. This site is at a gravel road with buried pipe at about $4 \mathrm{ft}$ depth. The top image was taken in the smooth wheel path of the road whereas the bottom image was taken a couple of feet away over the center of the road where there was rough gravel. There is more return from the surface and more distortion (fuzziness) in the image of the rough surface as compared with the smooth surface. Note that the pipe appears to have shifted a few feet to the left in the bottom image as compared to the top image. This is because the pipe was not laid in perpendicular to the road.

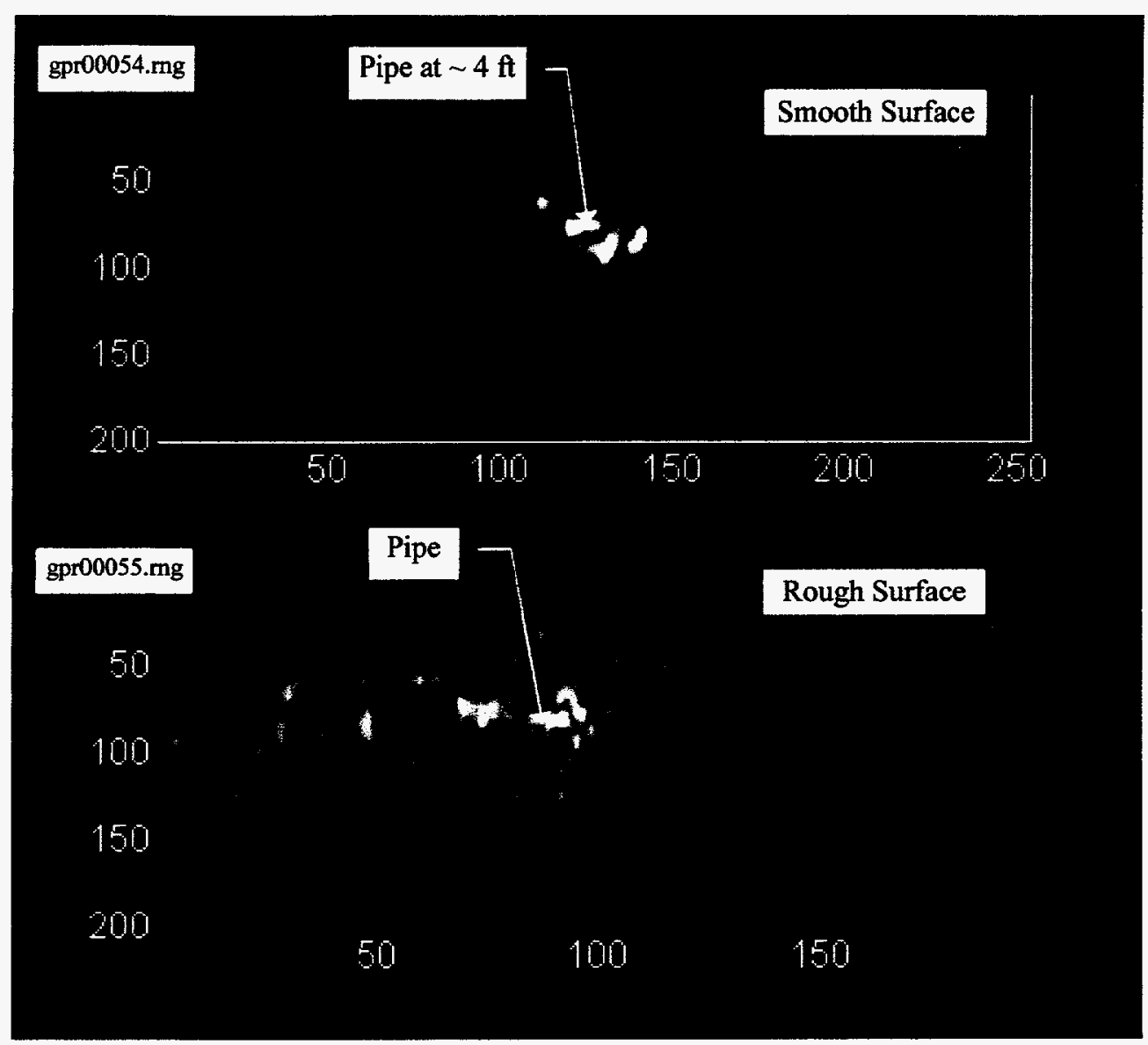

Figure 19: Effect of Surface Roughness over Pipe 
XIV. Findings-

A. GPR can detect transition from one subsurface feature to another, as in going from one rock type to another.

B. A wide beamwidth antenna GPR can be used to determine the dielectric constant of the subsurface material if a point target hyperbola is found in the image. Knowledge of the dielectric constant can be used to estimate the identity the subsurface material or the water content in which the point target is embedded. Any apriori knowledge or physical sampling of the subsurface would enhance this process.

C. Use a dielectric 'spacer' between the antenna and ground to move the antenna mismatch response (distortion) away from near-surface targets.

D. To produce high quality GPR images, it is very important to have good antenna coupling with the surface. This means that it may be necessary to prepare a site by cleaning off or blading smooth the surface.

E. For the FM-CW GPR system used in this project it was found that a $\sim 1$ Ghz frequency bandwidth, from $\sim 10 \mathrm{Mhz}$ to $1 \mathrm{Ghz}$, produced the best images while maintaining good penetration depth for the depths of interest in this study $(\sim 10 \mathrm{ft}$. max.). $1 \mathrm{Ghz}$ frequency bands up to 350 Mhz to 1350 Mhz were also found to work well. Larger bandwidths like 3 $\mathrm{Ghz}$ (300 Khz to $3 \mathrm{Ghz}$ ), have the potential for better resolution of nearsurface targets, however multipath clutter tends to increase. A $500 \mathrm{Mhz}$ bandwidth (10 Mhz to $500 \mathrm{Mhz}$ ) system has better depth penetration, however resolution in the image starts to suffer.

F. To allow for polarization dependent effects, multiple scan lines with different orientations should be made in surveying a GPR site. Consideration should also be given to the polarization characteristics of the antennas being used and to the suspected polarization characteristics of the subsurface targets. The antennas should be oriented in a manner to maximize the response of the targets. Ideally one would have an antenna that physically or electrically rotates as it scans, to enhance the probability of detecting polarization sensitive targets like pipes, etc.

G. A consistent calibration technique for the GPR system was not found. Surface conditions \& how antenna response is affected, varies widely from site to site. GPR performance should be evaluated at each site.

H. It is very helpful to change the color schemes to bring out different features in GPR images. Changing color schemes is a way to reduce clutter in images from a visual standpoint. Great use of this capability (in MATLAB) was made during the project. Use sunlight readable display.

I. Narrow beamwidth antennas can produce high quality sub-surface images if the surface is smooth. However the broad beamwidth antennas can produce acceptable quality images even with the characteristic hyperbola target responses. These hyperbola signal responses can even be used to gain information about the dielectric of the surrounding material. 
Narrow beamwidth antennas can have more loss than wide beamwidth antennas due to the dielectric material used to focus the beam. More RF gain may be required to compensate for this effect.

Wide beamwidth antennas can potentially receive signals from above the ground as well as below, whereas narrow beamwidth antennas are typically focused downward. This means that wide beamwidth antennas can be more susceptible to clutter generated from above ground targets. This fact may favor narrow beamwidth antennas in applications where the antenna has to be close to machinery.

J. An advantage of FM-CW GPR system with wide bandwidth antennas over an impulse GPR system is that the frequency bandwidth can be readily changed to maximize the desired GPR image response. Range response resolution and depth of penetration characteristics can be traded off to achieve the best image possible.

K. The Excavator moves slowly enough to allow for real-time signal processing of multi-polarization data, as well for image analysis.

XV. Recommendation for Future Research-

A. Additional research is recommended into the design of an optimum antenna system for use in characterizing excavation sites and use on trenching machinery. An antenna / GPR system that can dynamically change it's beamwidth, polarization and bandwidth would be most useful since site characteristics vary so much.

Possibly a synthetic aperture antenna design could be used to achieve the advantages of both narrow and wide beam antenna patterns. Narrow beam used for high quality imaging and wide beam for target detection and dielectric constant measurements.

A GPR with variable bandwidth capability would allow the operator to optimize the response of the GPR depending on the surface conditions and sub-surface target characteristics. Wide bandwidth would be used to resolve small targets near the surface, smaller bandwidths with low start frequencies would be used for greater depth penetration and larger target structures. Also the smaller bandwidth and lower start frequencies would tend to reduce the effects of surface clutter reflectors.

A continually varying antenna, physically rotating or electrically switched between polarization states, would improve the probability of detecting polarization dependent target structures such as pipes. It would also give better indication of transitions zones in going from one type of subsurface material to another.

B. Use of four dimensional (4-D) images could possibly improve the interpretation capability of an operator. These "volume" images would be generated from a matrix that includes three physical axes coordinates and one GPR intensity value. The physical axes would locate the range cell in space, and at that location the intensity of the reflection would be color modulated to represent the strength of the return. Multiple parallel GPR scans would be required to build-up the "volume" image. 
XVI. Recommendations for GPR Systems-

\begin{tabular}{|c|c|c|}
\hline PARAMETER & OPTION & COMMENT \\
\hline Power / Sensitivity & Target site dependent. & $\begin{array}{l}\text { System needs to be scanned over a similar } \\
\text { site with some known quantities to assess } \\
\text { the ability of the GPR to penetrate to the } \\
\text { required depth. The ability of GPR to } \\
\text { penetrate will vary widely from site to site. }\end{array}$ \\
\hline Bandwidth (FM-CW GPR) & $1000 \mathrm{Mhz}$ & $\begin{array}{l}\text { Provides good image resolution for narrow } \\
\text { beamwidth, FM-CW GPR systems. Must } \\
\text { use pre-FFT windowing (Hanning, etc.) }\end{array}$ \\
\hline $\begin{array}{l}\text { RF Frequency - } \\
\text { * FM-CW GPR - } \\
\text { * Impulse GPR - }\end{array}$ & $\begin{array}{l}\text { * } 200 \mathrm{Mhz}-1200 \mathrm{Mhz} \\
\text { * } 500 \mathrm{Mhz}\end{array}$ & $\begin{array}{l}\text { Both provided good penetration to } 10 \text { foot } \\
\text { depths for sites evaluated in this project. }\end{array}$ \\
\hline Antenna Type - & $\begin{array}{l}\text { * Broad beam - } \\
\text { * Narrow beam - }\end{array}$ & $\begin{array}{l}\text { * Best for general GPR use ( point target } \\
\text { detection, } e_{\mathrm{r}} \text { estimates ) } \\
\text { * Best for generation of high quality images } \\
\text { if sub-surface features are generally } \\
\text { known (pipes) } \\
\text { * Use dielectric spacer under antennas to } \\
\text { improve signal coupling with ground }\end{array}$ \\
\hline Polarization - & Linear or Circular & $\begin{array}{l}\text { For either, need to scan GPR sites from } \\
\text { different directions to improve probability } \\
\text { of detecting transitions and "point" targets }\end{array}$ \\
\hline Data Registration & $\begin{array}{l}\text { Store range cell physical } \\
\text { location with GPR return } \\
\text { intensity }\end{array}$ & $\begin{array}{l}\text { Precise location along or cross track (wheel } \\
\text { counter, tape measure), \& large scale } \\
\text { location (GPS) }\end{array}$ \\
\hline Display & $\begin{array}{l}\text { GPR image displayed: } \\
\text { * Color } \\
\text { * STC \& Zoom } \\
\text { * Detrend } \\
\text { * Dielectric Calculation } \\
\text { * "4-D" Volume image } \\
\text { display }\end{array}$ & $\begin{array}{l}\text { Sunlight readable } \\
\text { * Helpful in image interpretation. } \\
\text { * Control of gain vs. range allows operator } \\
\text { to enhance the range cells of most interest } \\
\text { * This feature will remove some effects of } \\
\text { antenna response \& of consistent } \\
\text { reflections through out a GPR image. } \\
\text { * Operator selects } 2 \text { points on hyperbola } \\
\text { using a cursor, computer calculates } \mathrm{e}_{\mathrm{r}} \text { Or } \\
\text { could use image analysis software. } \\
\text { * Another option to help with image } \\
\text { interpretation by the operator. }\end{array}$ \\
\hline Site Surface & $\begin{array}{l}\text { Smooth, } \\
\text { No Vegetation }\end{array}$ & $\begin{array}{l}\text { Blade it for best coupling of antenna to the } \\
\text { ground. Required for good GPR images. }\end{array}$ \\
\hline Site Subsurface & Apriori Information & $\begin{array}{l}\text { Especially useful in image interpretation } \\
\text { and evaluation of GPR performance. }\end{array}$ \\
\hline
\end{tabular}

Table 4: GPR System Recommendations 
APPENDIX A - Image Descriptions

Three different, external, RF Amplifiers were used during the project. The designation for what was used at each site is listed:

$\underline{\text { RF Amp Index \# }}$

0

1

2

3

\section{$\underline{\text { RF Amp }}$}

HP8753 Network Analyzer only (no amp) HP8347A, 8 dB Gain, 1/10W max.

Avantek APG-2052, 33 dB Gain, 1/2W max EIN Model 603L, $39 \mathrm{~dB}$ Gain, 3W max.

Image Descriptions:

\begin{tabular}{|c|c|c|c|c|c|c|}
\hline $\begin{array}{c}\text { Figure } \\
\#\end{array}$ & Filename & Site Description & $\begin{array}{l}\text { Time } \\
\text { Span } \\
\text { (nS) }\end{array}$ & $\underset{\#}{\mathbf{R F}}$ & $\begin{array}{l}\text { Start } \\
\text { Freq } \\
\text { (Mhz) }\end{array}$ & $\begin{array}{l}\text { BW } \\
\text { (Mhz }\end{array}$ \\
\hline 1 & gpr00086.mg & $\begin{array}{l}\text { TTC/MSB: 6" Pipe @ } \sim 6 \mathrm{ft} \text { in earth filled trench } \\
\text { under gravel, transitions to pavement at right }\end{array}$ & 40 & 2 & 200 & 1000 \\
\hline 3 & GSSI Image & New Golf Course: dry, no veg, smooth, coleache & na & na & 500 & na \\
\hline 4 & GSSI Image & Parking Lot: smooth black-top pavement & na & na & 500 & na \\
\hline 5 & S\&S Image & Construction Site: dry, no veg, smooth, soil & $\overline{\text { na }}$ & $\overline{\text { na }}$ & 450 & na \\
\hline$\overline{7}$ & gpr00225.mg & $\begin{array}{l}\text { TTC_1st floor bsmt image: air ducts, large pipes, } \\
\text { flooring support structures, transition to earth fill }\end{array}$ & 50 & 2 & 300 & 3000 \\
\hline 7 & gpr00234.mg & $\begin{array}{l}\text { TTC_1st floor bsmt image: air ducts, large pipes, } \\
\text { flooring support structures, transition to earth fill }\end{array}$ & 50 & 2 & 10 & 1000 \\
\hline 7 & gpr00236.mg & $\begin{array}{l}\text { TTC_1st floor bsmt image: air ducts, large pipes, } \\
\text { flooring support structures, transition to earth fill }\end{array}$ & 50 & 2 & 10 & 500 \\
\hline 8 & gpr00057.mg & $\begin{array}{l}\text { Gravel Rd by Bldg_16: 6" Pipe @ } \sim 4 \mathrm{ft} \text {, smooth } \\
\text { surface, with 6dB RF attenuator }\end{array}$ & 40 & 2 & 350 & 1000 \\
\hline 8 & gpr00054.mg & $\begin{array}{l}\text { Gravel Rd by Bldg_16: 6" Pipe in earth filled } \\
\text { trench @ } \sim 4 \mathrm{ft} \text { depth, smooth surface, no } 6 \mathrm{~dB} \text { RF } \\
\text { attenuator }\end{array}$ & 40 & 2 & 350 & 1000 \\
\hline $9 a$ & gpr00072.mg & $\begin{array}{l}\text { TTC/MSB: 6" Pipe @ } \sim 6 \mathrm{ft} \text { in earth filled trench } \\
\text { under gravel, transitions to pavement at right, } \\
\text { xmit antenna in front of receive antenna }\end{array}$ & 40 & 2 & 200 & 1000 \\
\hline $9 b$ & gpr00075.mg & $\begin{array}{l}\text { TTC/MSB: 6" Pipe@ }-6 \mathrm{ft} \text { in earth filled trench } \\
\text { under gravel, transitions to pavement at right, } \\
\text { xmit/receive antennas are side-by-side }\end{array}$ & 40 & 2 & 200 & 1000 \\
\hline 10 & gpr00217.mg & $\begin{array}{l}\text { TTC_1st floor bsmt image: from earth fill sub- } \\
\text { surface to floor support structure (bsmt ceiling), } \\
\text { xmit antenna in front of receive antenna }\end{array}$ & 50 & 2 & 0.3 & 3000 \\
\hline 10 & gpr00218.rng & $\begin{array}{l}\text { TTC_1st floor bsmt image: from earth fill sub- } \\
\text { surface to floor support structure (bsmt ceiling), } \\
\text { xmit/receive antennas are side-by-side }\end{array}$ & 50 & 2 & 0.3 & 3000 \\
\hline
\end{tabular}


APPENDIX A - Image Descriptions (cont)

\begin{tabular}{|c|c|c|c|c|c|c|}
\hline $\begin{array}{l}\text { Figure } \\
\#\end{array}$ & Filename & Site Description & $\begin{array}{c}\text { Time } \\
\text { Span } \\
(\mathrm{nS}) \\
\end{array}$ & $\begin{array}{c}\mathbf{R F} \\
\text { Amp } \\
\# \\
\end{array}$ & $\begin{array}{c}\text { Start } \\
\text { Freq } \\
\text { (Mhz) } \\
\end{array}$ & BW \\
\hline 11 & gpro0075.mg & $\begin{array}{l}\text { TTC/MSB: 6" Pipe @ 6 ft in earth filled trench } \\
\text { under gravel, transitions to pavement at right, } \\
\text { xmit/receive antennas are side-by-side }\end{array}$ & 40 & 2 & 200 & 1000 \\
\hline 12 & gpro0029.mg & $\begin{array}{l}\text { Gravel Rd by Bldg_16: 6" Pipe @ } \sim 4 \mathrm{ft} \text {, rough } \\
\text { gravel surface }\end{array}$ & 40 & 1 & 200 & 1000 \\
\hline 13 & gpro0219.mg & $\begin{array}{l}\text { TTC_1st floor bsmt image: from earth fill, } \\
\text { transition to bsmt room, large pipes, flooring } \\
\text { support structures, metal air duct, Max TDR } \\
\text { Window }\end{array}$ & $\overline{50}$ & $\overline{2}$ & 0.3 & 3000 \\
\hline 13 & gpr00217mg & $\begin{array}{l}\text { TTC_1st floor bsmt image: from earth fill, } \\
\text { transition to bsmt room, large pipes, flooring } \\
\text { support structures, metal air duct, Nominal TDR } \\
\text { window }\end{array}$ & 50 & 2 & 0.3 & 300 \\
\hline 13 & gpr00220ng & $\begin{array}{l}\text { TTC_1st floor bsmt image: from earth fill, } \\
\text { transition to bsmt room, large pipes, flooring } \\
\text { support structures, metal air duct, Min TDR } \\
\text { Window }\end{array}$ & 50 & 2 & 0.3 & 300 \\
\hline$\overline{14}$ & gpro0015.mg & $\begin{array}{l}\text { Gravel Rd by Bldg_16: 6" Pipe @ } \sim 4 \mathrm{ft} \text {, smooth } \\
\text { surface }\end{array}$ & 30 & $\mathbf{0}$ & 200 & 1000 \\
\hline$\overline{14}$ & gpro0014.mg & $\begin{array}{l}\text { Gravel Rd by Bldg_16: 6" Pipe @ 4 ft, rough } \\
\text { gravel surface, } 1.5 \mathrm{ft} \text { over \& parallel to } \\
\text { gpro0015.mg }\end{array}$ & 30 & $\begin{array}{l}0 \\
0\end{array}$ & 200 & 1000 \\
\hline$\overline{14}$ & gpro0011.mg & $\begin{array}{l}\text { Gravel Rd by Bldg_16: 6" Pipe @ 4 ft, rough } \\
\text { gravel surface, } 4 \mathrm{ft} \text { over \& parallel to } \\
\text { gpr00015.mg }\end{array}$ & 30 & 0 & 200 & 1000 \\
\hline$\overline{15}$ & $\begin{array}{c}\text { gpr00103.mg } \\
\& \\
\text { gpr00104.mg } \\
\end{array}$ & $\begin{array}{l}\text { Smith Farm: transition from buried rock shelf to } \\
\text { erosion-fill, tall-grass surface, } \sim 1 \mathrm{ft} \text { samples }\end{array}$ & 40 & $\overline{2}$ & 200 & 1000 \\
\hline 16,17 & gpr00215.mg & $\begin{array}{l}\text { Bannister_Rd / HiWay_71 road cut: flat, } \\
\text { relatively smooth gravel surface, minimum veg. }\end{array}$ & 50 & 2 & 0.3 & 3000 \\
\hline 18 & gpro0053.mg & $\begin{array}{l}\text { Near Bldg_16: transition from relatively smooth } \\
\text { gravel surface to very rough gravel surface with } \\
\text { some veg, buried pipes are present }\end{array}$ & 40 & $\overline{2}$ & 200 & 1000 \\
\hline 19 & gpr00054.mg & $\begin{array}{l}\text { Gravel Rd by Bldg_16: 6" Pipe in earth filled } \\
\text { trench @ } \sim 4 \mathrm{ft} \text { depth, smooth surface }\end{array}$ & 40 & 2 & 350 & 1000 \\
\hline 19 & gpr00055.mg & $\begin{array}{l}\text { Gravel Rd by Bldg 16: 6" Pipe in earth filled } \\
\text { trench @ } 4 \mathrm{ft} \text { depth, rough gravel surface }\end{array}$ & 40 & 2 & 350 & 1000 \\
\hline
\end{tabular}

Notel- *.mg files have been processed using STC gain to enhance targets at greater depths.

Note2- Most runs were made with the receive antenna trailing the transmit antenna. 


\section{APPENDIX B - AlliedSignal Ground Penetrating Radar (GPR) Photo}

The AlliedSignal GPR system consists of a notebook computer, RF amplifier, HP8753 RF Network Analyzer, and dual circular antennas. The antennas are mounted to a sled that is pulled across the target site. The computer program triggers the analyzer to take Time Domain Reflection (TDR) samples as the sled is moved. These samples are stored in a data matrix file for later processing into a GPR image. The system runs off of $115 \mathrm{Vac}$ power from a portable generator.

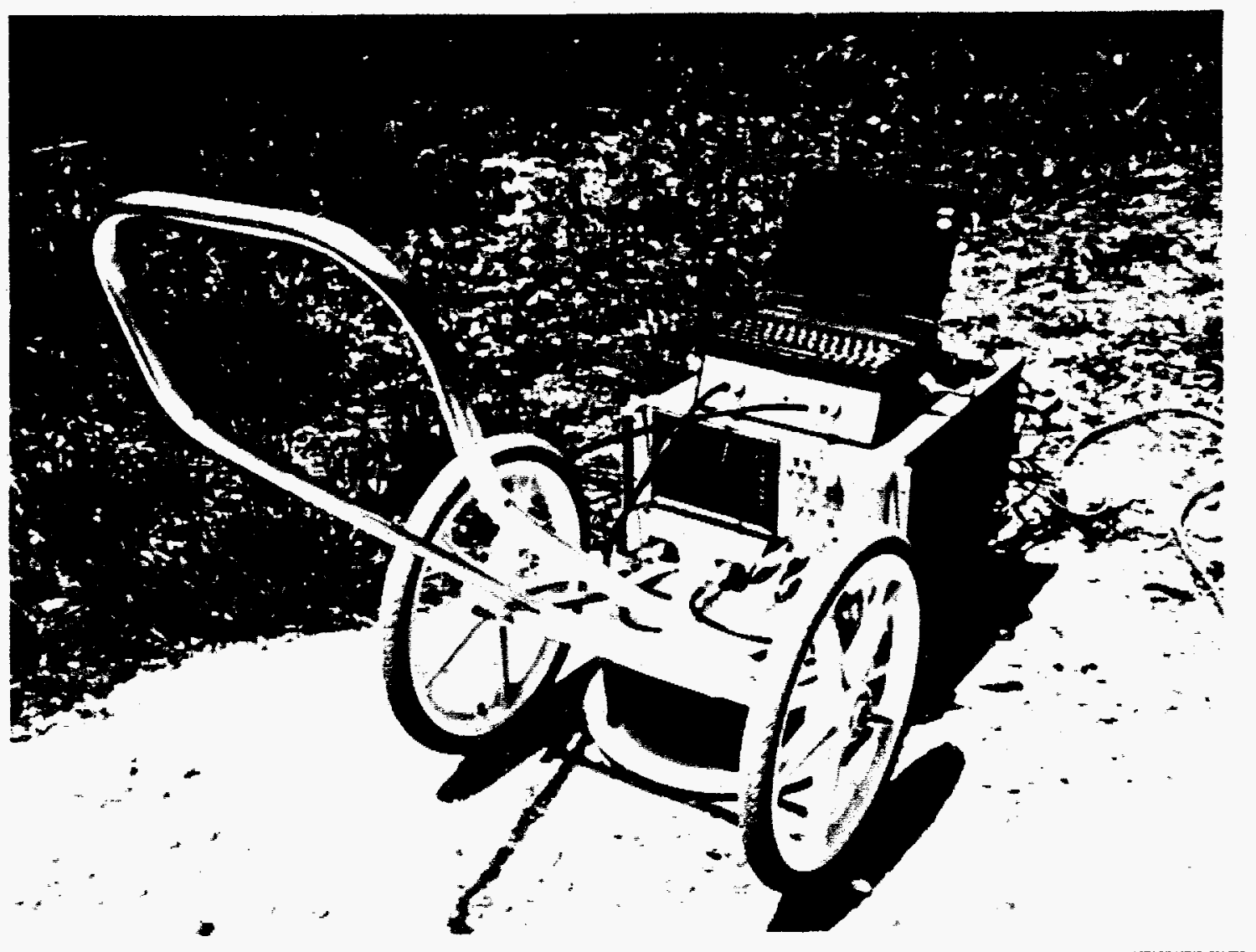

Figure 20 - AlliedSignal GPR System Photo 